\title{
¿Land-Atmosphere Coupling Sensitivity to GCMs Resolution: A Multimodel Assessment of Local and Remote Processes in the Sahel Hot Spot
}

\author{
Omar V. MÜller, ${ }^{a, b, f}$ Pier Luigi Vidale, ${ }^{a, b}$ Benoît VANnière, ${ }^{a, b}$ Reinhard Schiemann, ${ }^{a, b}$ \\ Retish Senan, ${ }^{\mathrm{c}}$ Reindert J. HaArsma, ${ }^{\mathrm{d}}$ and Johann H. JungClaus ${ }^{\mathrm{e}}$

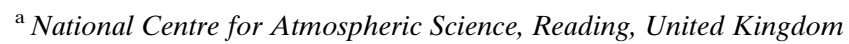 \\ ${ }^{\mathrm{b}}$ Department of Meteorology, University of Reading, Reading, United Kingdom \\ ${ }^{\mathrm{c}}$ European Centre for Medium-Range Weather Forecasts, Reading, United Kingdom \\ ${ }^{\mathrm{d}}$ Royal Netherlands Meteorological Institute (KNMI), De Bilt, Netherlands \\ e The Ocean in the Earth System, Max Planck Institute for Meteorology, Hamburg, Germany
}

(Manuscript received 26 April 2020, in final form 19 October 2020)

\begin{abstract}
Land-atmosphere interactions are often interpreted as local effects, whereby the soil state drives local atmospheric conditions and feedbacks originate. However, nonlocal mechanisms can significantly modulate land-atmosphere exchanges and coupling. We make use of GCMs at different resolutions (low $\sim 1^{\circ}$ and high $\sim 0.25^{\circ}$ ) to separate the two contributions to coupling: better represented local processes versus the influence of improved large-scale circulation. We use a two-legged metric, complemented by a process-based assessment of four CMIP6 GCMs. Our results show that weakening, strengthening, and relocation of coupling hot spots occur at high resolution globally. The northward expansion of the Sahel hot spot, driven by nonlocal mechanisms, is the most notable change. The African easterly jet's horizontal wind shear is enhanced in JJA due to better resolved orography at high resolution. This effect, combined with enhanced easterly moisture flux, favors the development of African easterly waves over the Sahel. More precipitation and soil moisture recharge produce strengthening of the coupling, where evapotranspiration remains controlled by soil moisture, and weakening where evapotranspiration depends on atmospheric demand. In SON, the atmospheric influence is weaker, but soil memory helps to maintain the coupling between soil moisture and evapotranspiration and the relocation of the hot spot at high resolution. The multimodel agreement provides robust evidence that atmospheric dynamics determines the onset of land-atmosphere interactions, while the soil state modulates their duration. Comparison of precipitation, soil moisture, and evapotranspiration against satellite data reveals that the enhanced moistening at high resolution significantly reduces model biases, supporting the realism of the hot-spot relocation.
\end{abstract}

KEYWORDS: Africa; Atmosphere-land interaction; General circulation models; Model evaluation/performance

\section{Introduction}

The land surface is recognized as a key driver of climate variability and predictability at different time scales (Koster et al. 2000; Guo et al. 2011, and references therein). Changes in soil and/ or surface conditions can affect land-atmosphere feedbacks and, therefore, regional climate (Dirmeyer 2000). There are particular regions of Earth with strong land-atmosphere coupling, where the land surface state, represented by soil moisture, has a direct effect on the overlying atmosphere. In these areas, soil moisture modulates land-atmosphere feedbacks through the exchanges of latent and sensible heat fluxes (Koster et al. 2004). It also interacts and modifies runoff, regulating changes in river flows. Through these processes, the state of the land-atmosphere coupling can

DDenotes content that is immediately available upon publication as open access.

\footnotetext{
${ }^{\mathrm{f}}$ Current affiliation: Consejo Nacional de Investigaciones Científicas y Técnicas, Centro de Estudios de Variabilidad y Cambio Climático, Facultad de Ingeniería y Ciencias Hídricas, Universidad Nacional del Litoral, Ciudad Universitaria, Santa Fe, Argentina.
}

Corresponding author: Omar V. Müller, ovmuller@unl.edu.ar modify the persistence and intensity of droughts or wet spells (Seneviratne et al. 2006).

Given the critical role of land-atmosphere interactions in the climate system, some community-wide initiatives have resulted in significant advances in evaluation of global climate models (GCMs) performance in reproducing the involved processes. In particular, the Global Land-Atmosphere Coupling Experiment (GLACE) 1 and 2 led the intercomparison of the coupling strength across a broad range of GCMs (Koster et al. 2002, 2004; Seneviratne et al. 2006; Koster et al. 2010, 2011; Guo et al. 2011; Seneviratne et al. 2013). The GLACE results show an overall consensus in the identification of spatial land-atmosphere hot spots but highlight that their intensity and location depend on the interannual variability of soil moisture that alter soil moisture-evapotranspiration processes (Guo et al. 2006; Guo and Dirmeyer 2013). Soil moisture is highly sensitive to model parameterization, a feature that leads to significant dispersion in the coupling strengths intensity among GCMs (Koster et al. 2006). Then, the Local Land-Atmosphere Coupling (LoCo) project (Santanello et al. 2018) focused the understanding of land-atmosphere related processes through the development of coupling metrics and diagnostics (Santanello et al. 2011b; Findell et al. 2015; Guillod et al. 2015). By evaluating six different combinations of land surface models and planet boundary layer (PBL) schemes, LoCo suggests that the choice of land surface models is critical for dry regimes, while the PBL scheme has a comparable influence during wet regimes (Santanello et al. 2011a). 
The underlying conceptual framework of most of the landatmosphere coupling studies considers the soil state as the onset factor of a chain of processes that determine the atmospheric conditions. For instance, Eltahir (1998) presents the hypothesis that "wet soil moisture conditions over any large region should be associated with relatively large boundary layer moist static energy, which favors the occurrence of more rainfall." Koster and Suarez (2003) and Findell et al. (2015) suggest that in regions of strong coupling like North America, the summer convective rainfall is highly sensitive to large soil moisture anomalies. Similarly, Santanello et al. (2011b) describe the complex set of dependent relationships in the PBL height as a key element that connects the soil moisture anomalies with the subsequent precipitation anomalies. At the global scale, Taylor et al. (2012) showed observational evidence that soil moisture heterogeneity can influence the development of convective storms, but they also point out that coarse-resolution models cannot represent mesoscale soil moisture structures or their effects on convection. Similarly, Guillod et al. (2015) found that precipitation events tend to occur in the presence of wet and heterogeneous soil moisture conditions, albeit located over comparatively drier patches. Moreover, it has been shown in modeling studies that soil wetness acts as a precursor of extreme maximum temperature and drought in the European region (Fischer et al. 2007; Zampieri et al. 2009; Quesada et al. 2012; Ukkola et al. 2018; van der Linden et al. 2019).

Despite the importance of atmospheric moisture fluxes in determining precipitation patterns that feed soil moisture, the remote sources of moisture are rarely addressed in landatmosphere coupling studies. Holgate et al. (2019) have shown that there are aspects of atmospheric flow that make the simple picture of a $1 \mathrm{D}$ mechanism for land-atmosphere coupling too simplistic. They evaluated the correlation between soil moisture and next day precipitation in Australia, with and without upholding the 1D assumption. To distinguish whether the grid cell air mass is transported from outside or not, they prescribed a wind speed threshold for the transport that is proportional to resolution. They found that, while there are high soil moistureprecipitation correlations, the moisture that feeds precipitation comes mostly from surrounding grid cells. This effect gradually increases when the resolution is enhanced progressively from $2.5^{\circ}$ to $0.05^{\circ}$. The Great Plains in summer is one of the coupling hot spots that have shown sensitive to remote sources of moisture. In particular, Ruiz-Barradas and Nigam (2013) found that moisture transport dominates over evapotranspiration in summer precipitation variability. Similarly, Su et al. (2014) reported that large-scale atmospheric disturbances play a significant role in the land-atmosphere feedback, while Welty and Zeng (2018) and Welty et al. (2020) found that soil moisture and precipitation become positively correlated under enhanced synoptic influence. Moreover, Basara and Christian (2018) found that the variability of coupling location was large both within-season and at the interannual scale, and such variability is determined by nonlocal factors. Wei et al. (2016) showed similar results for the United States, but also extended the evaluation to the entire globe, concluding that atmospheric moisture flux is more important than soil moisture for precipitation, although the impact of soil wetness becomes larger over certain transitional regions (e.g., Sahel). Using a moisture tracking method Wei and Dirmeyer (2019) found that precipitation in West Africa is sensitive to both local and remote evapotranspiration, while East Africa is mostly driven by local sources of moisture. These previous observation-based findings provide key metrics for assessing CMIP model performance and trustworthiness, as well as, highlighting the need to advance in the understanding of land-atmosphere coupling from a broader perspective that considers both, local and nonlocal mechanisms, as potential source of coupling changes. Because GCMs are essential tools for prediction, and because society is reliant on predictions of biomass and water resources, it is important to understand whether the current generation of GCMs can simulate the correct land-atmosphere coupling for the correct reasons.

The Process-Based Climate Simulation: Advances in HighResolution Modeling and European Climate Risk Assessment (PRIMAVERA) project offers the possibility to assess the climate system with a new generation of advanced and wellevaluated high-resolution global climate models. The resolution enhancement has a priori four effects on GCMs, with a potential impact on land-atmosphere coupling. First, the spatial variability of prescribed land surface properties necessarily increases with model resolution enhancement, leading to a higher heterogeneity in their spatial distribution. This modifies land surface processes such as soil infiltration, evaporation, and plant interception and transpiration, which affect vertical water and energy fluxes at surface (Müller et al. 2014). Second, it has been shown in resolution sensitivity studies that higher-resolution atmospheric models enhance ocean-land transport, producing more realistic mesoscale circulation patterns, synoptic systems, and convective storms (Demory et al. 2014; Vannière et al. 2019). These changes are in general attributed to a better resolved orography, which allows to simulate more accurate moisture transport, improving the precipitation timing and distribution. Third, interactions between intense, organized rainfall (e.g., convective storms in Sahel) and dynamics are more effective when increasing resolution to about $25 \mathrm{~km}$ in GCMs with parameterized convection (Vellinga et al. 2016). Fourth, the enhanced regional transport in the intertropical convergence zone due to the changes in the easterlies, as well as instability in the easterlies (Vannière et al. 2019). The first effect is a local source of coupling change, while the last three are largescale processes with potential impact on land-atmosphere interactions.

New CMIP6 High Resolution Model Intercomparison Project (HighResMIP) GCMs experiments available through PRIMAVERA are designed specifically to investigate the role of model resolution for climate simulation (see section $2 b$ ). The goal of our study is to perform a multimodel, process-based evaluation of the sensitivity of land-atmosphere coupling to the resolution of CMIP6-HighResMIP GCMs, both atmosphere-only and coupled. With this aim, we 1) quantify the seasonal landatmosphere coupling for a set of global simulations at different resolution, 2) advance in the understanding of dynamical processes behind the interplay between land and atmosphere over the Sahel, and 3) evaluate whether the enhancement of GCMs horizontal 
TABLE 1. GCM configurations.

\begin{tabular}{|c|c|c|c|c|c|c|c|}
\hline \multirow[b]{2}{*}{ Model } & \multirow[b]{2}{*}{ Simulation type } & \multicolumn{2}{|c|}{ Horizontal resolution at $50^{\circ} \mathrm{N}$} & \multicolumn{2}{|c|}{ Ocean resolution } & \multirow{2}{*}{$\begin{array}{c}\text { No. of } \\
\text { atmospheric levels }\end{array}$} & \multirow{2}{*}{$\begin{array}{c}\text { Soil layer } \\
\text { thickness }(\mathrm{cm})\end{array}$} \\
\hline & & Low & High & Low & High & & \\
\hline EC-Earth3 & AMIP & $\mathrm{T} 255(80 \mathrm{~km})$ & T511 (39 km) & - & - & 91 & $7,21,72,155$ \\
\hline HadGEM-GC31 & AMIP & N96 $(135 \mathrm{~km})$ & $\mathrm{N} 512(25 \mathrm{~km})$ & - & - & 85 & $10,25,65,200$ \\
\hline ECMWF-IFS & AMIP & Tco199 $(50 \mathrm{~km})$ & Tco199 $(25 \mathrm{~km})$ & - & - & 91 & $7,21,72,155$ \\
\hline MPI-ESM-1-2 & AMIP & $\mathrm{T} 127(64 \mathrm{~km})$ & $\mathrm{T} 255(32 \mathrm{~km})$ & - & - & 95 & $6,26,92,288,572$ \\
\hline HadGEM-GC31 & COUPLED & N96 (135 km) & N512 (25 km) & ORCA1 & ORCA025 & 85 & $10,25,65,200$ \\
\hline ECMWF-IFS & COUPLED & Tco199 $(50 \mathrm{~km})$ & Tco399 $(25 \mathrm{~km})$ & ORCA1 & ORCA025 & 91 & $7,21,72,155$ \\
\hline MPI-ESM-1-2 & COUPLED & $\mathrm{T} 127(64 \mathrm{~km})$ & $\mathrm{T} 255(32 \mathrm{~km})$ & TP04 & ТP04 & 95 & $6,26,92,288,572$ \\
\hline
\end{tabular}

resolution improves the simulation of key variables related to land-atmosphere coupling processes. The comparison between low- and high-resolution GCM simulations enables the investigation of both sources of land-atmosphere coupling changes: local effects originated by increased variability in land surface parameters and nonlocal effects caused by changes in atmospheric moisture fluxes, precipitation patterns, and/or the dynamics of the easterly flow. The characteristics of the GCMs and observational data, the coupling index, and the process-based approach are presented in section 2. Section 3 introduces the resolution effects on land-atmosphere coupling strength at global scale, while section 4 focus the analysis on a region of growing scientific interest as the Sahel hot spot. A summary discussion and concluding remarks are presented in section 5 .

\section{Data and methodology}

\section{a. Region of interest}

The coupling diagnostics and their sensitivity to resolution are evaluated at the global scale. However, a comprehensive process-based analysis is done with a particular focus to the Sahel region. The Sahel is a recognized land-atmosphere coupling hot spot particularly interesting to evaluate as it is affected by unique meteorological features that prevent simply extrapolating the mechanistic reasoning found in other hot spots of the world. The Sahel is a transition belt between the Sahara Desert to the north and the humid savannahs to the south, extending from the Atlantic coast to the Red Sea. The region is dominated by a complex coupled ocean-landatmosphere system that leads to a summer monsoon climate (Lafore et al. 2010; Sylla et al. 2013). One of the features that plays a critical role during the rainy season is the strong midtropospheric $(\sim 600 \mathrm{hPa})$ zonal winds called the African easterly jet. It drives the generation, growth, and propagation of the African easterly waves (AEWs). The AEWs are disturbances around the zonal circulation, which can produce convective rainfall over West Africa, but also can travel into the tropical Atlantic and further develop into tropical cyclones (Carlson 1969a,b; Burpee 1972; Diedhiou et al. 1999, among others). Many authors also suggest that soil moisture anomalies have a strong impact on Sahelian rainfall, through a positive soilprecipitation feedback (Rowell et al. 1995; Douville et al. 2007; Moufouma-Okia and Rowell 2010). In this context, the correct representation of the interplay among the climate components in climate models is crucial to understanding the land-atmosphere coupling processes in Sahel.

\section{b. Model simulations}

A set of climate model experiments produced within the framework of HighResMIP, version 1.0 (v1.0), for CMIP6 (Haarsma et al. 2016) is used to evaluate the land-atmosphere coupling. The experiments include simulations at low horizontal resolution (LR) and high horizontal resolution (HR) using four GCMs under two different configurations: atmosphere-land (AMIP) and ocean-atmosphere-land (COUPLED) runs. The GCMs are EC-Earth3 (only AMIP type); Hadley Centre Global Environment Model, version 3 (HadGEM3); European Centre for Medium-Range Weather Forecasts Integrated Forecast System (ECMWF-IFS); and MPI-ESM-1-2. The runs are organized in four multimodel ensembles: 1) AMIP LR (four models), 2) AMIP HR (four models), 3) COUPLED LR (three models), and 4) COUPLED HR (three models). As horizontal resolution is increased, the configuration for each model (e.g., vertical levels, parameterizations, schemes) remains identical. The resolution features of each model are presented in Table 1. The AMIP simulations are forced by HadISST2 daily SST at $0.25^{\circ}$ (Titchner and Rayner 2014). The period of simulation extends from January 1950 to December 2014.

EC-Earth3 (Hazeleger et al. 2010) is developed as part of a Europe-wide consortium lead by the Swedish Meteorological and Hydrological Institute (SMHI), while the simulations used on this work are provided by the Royal Netherlands Meteorological Institute [Koninklijk Nederlands Meteorologisch Instituut (KNMI)]. The atmospheric component is solved by a spectral model truncated at T255 (LR) and T511 (HR) with 91 vertical levels. The land surface component is H-TESSEL (Balsamo et al. 2009), which has four soil layers covering a total depth of $2.55 \mathrm{~m}$.

HadGEM3-GC31 (Williams et al. 2018) is provided by the Met Office. The HadGEM3 family of models comprises a range of specific model configurations incorporating different levels of complexity but with a common physical framework. The subversion GC31 uses the Unified Model (UM; Cullen 1991) with the global-atmosphere 7.1 configuration with a regular latitude/longitude grid at N96 (LR) and N512 (HR) with 85 vertical levels. The land surface is the Joint U.K. Land Environment Simulator (JULES; Best et al. 2011) with the global-land 7.1 configuration. It defines four soil layers up to 
$3.0 \mathrm{~m}$ depth. The ocean for the COUPLED runs is simulated with the Nucleus for European Modeling of the Ocean (NEMO; Madec et al. 2008) configuration global-ocean 6.0 with resolutions ORCA1 (LR) and ORCA025 (HR).

ECMWF-IFS (Roberts et al. 2018) is the European Centre for Medium-Range Weather Forecasts Integrated Forecast System, version 43r1. The atmospheric core uses a cubic octahedral reduced Gaussian grid at Tco199 (LR) and Tco399 with 91 vertical levels. The land surface model is the same as that used in ECEarth (H-TESSEL) with the same definition of layers. The ocean model for the COUPLED configuration is based on NEMO with the same grids used in HadGEM-GC31.

MPI-ESM-1-2 (Mauritsen et al. 2019) is the GCM of the Max Planck Institute for Meteorology. It is based on the components of ECHAM6 for atmosphere, JSBACH for land, and MPI-OM for ocean. ECHAM6 uses a quadratic Gaussian grid truncated at T127 (LR) and T255 (HR) with 95 vertical levels (Gutjahr et al. 2019). JSBACH defines five soil layers that reach a deep of $9.85 \mathrm{~m}$. The deepest layer, not included in the other land surface models, may increase the soil moisture memory in some areas, supplying wetter conditions in dry seasons by upward water transport to the root zone (Hagemann and Stacke 2015). MPI-OM is run at a common resolution of TP04 $\left(0.4^{\circ}\right)$ (Jungclaus et al. 2013).

\section{c. Evaluation datasets}

Despite the importance of weather and climate for the Sahel for the society and the economy, it is a region with a low density of in situ observations, in particular of soil moisture and latent heat. Moreover, Beck et al. (2017) showed that precipitation reanalysis products are poorly correlated with the few observations available in this part of Africa (correlation coefficients below 0.5 ). On the other hand, the statistical nature of the metrics used (see section $2 \mathrm{~d}$ ) requires long-term time series, a requirement that reanalyses and satellite data do not currently meet. These limitations prevent an assessment of our coupling metrics derived from GCMs with the same metrics derived from reanalysis or satellite products. Thus, to confirm whether the coupling processes that emerge from the high-resolution models are in better agreement with observations or not, we complement our analysis with a direct evaluation of key variables (precipitation, soil moisture and latent heat) with the most recent satellite-based products.

Precipitation is evaluated against Tropical Rainfall Measuring Mission (TRMM) 3B43_V7 (Huffman et al. 2007; TRMM 2011). The product is created using TRMM-adjusted merged microwaveinfrared precipitation rate, at a spatial resolution of $0.25^{\circ}$ and covers the period 1998-2014 with monthly time step. Soil moisture is compared with the European Space Agency Climate Change Initiative Soil Moisture (ESA CCI SM) v4.7 (Dorigo et al. 2017; Gruber et al. 2017, 2019). ESA CCI SM is a merged product of active and passive satellite soil moisture datasets optimally combined. It is a daily product available globally at $0.25^{\circ}$ from 2000 and estimates the soil moisture at few centimeters below surface (about $0.5-2-\mathrm{cm}$ depth) as volumetric water content. Latent heat is assessed with FLUXCOM remote sensing and meteorological data (RS+METEO) developed by the Max Planck Institute for Biogeochemistry (Jung et al. 2019). FLUXCOM $\mathrm{RS}+\mathrm{METEO}$ is a product developed with optimized machine learning methods that merges energy flux measurements from Flux Network (FLUXNET) towers with remote sensing and meteorological data to estimate the components of the energy balance at surface. The spatial resolution is $0.5^{\circ}$ and is available for the period 2001-13.

\section{d. Land-atmosphere coupling index}

Land-atmosphere coupling is understood, in this paper, as the complete pathway that involves the atmospheric response to changes in land surface conditions through the water cycle. The two-legged coupling metric is used to quantify the soil moisture-precipitation feedback pathway in each grid cell. It decomposes the complete pathway into two segments: the terrestrial leg [terrestrial coupling index (TCI); Dirmeyer 2011], which identifies areas where soil moisture changes drive surface flux variability, and the atmospheric leg [atmospheric coupling index (ACI); Dirmeyer et al. 2014], which identifies whether changes in a surface flux variable is able or not to drive changes in precipitation. The land-atmosphere hot spots are those regions where both segments of the coupling are strong, which guarantees a feedback from the atmosphere to the land completing the mechanistic loop (Guo et al. 2006).

The TCI is defined as

$$
\mathrm{TCI}=\frac{\operatorname{cov}(\theta, \lambda E)}{\sigma(\theta)},
$$

where $\operatorname{cov}(\theta, \lambda E)$ is the covariance between soil moisture $\theta$ and surface latent heat flux $\lambda E$ time series, and $\sigma(\theta)$ is the temporal standard deviation of soil moisture. Equation (1) has an intuitive mathematical interpretation when it is rewritten as TCI $=$ $m \sigma(\theta)$. The term $m=\operatorname{cov}(\theta, \lambda E) / \sigma^{2}(\theta)$ is the slope of the linear regression of the relationship between $\theta$ and $\lambda E$, while the term $\sigma(\theta)$ weights the slope by the soil moisture variability. The latter aims to smooth the index value on sites with large correlation and slope but nearly time-invariant soil moisture.

Similarly, the ACI is defined as

$$
\mathrm{ACI}=\frac{\operatorname{cov}(\lambda E, P)}{\sigma(\lambda E)},
$$

where $\operatorname{cov}(\theta, \lambda E)$ is the covariance between latent heat flux and precipitation $P$, and $\sigma(\lambda E)$ is the temporal standard deviation of latent heat. As for TCI, the Eq. (2) can be interpreted as the slope of the linear regression between $\lambda E$ and $P$ weighted by the standard deviation of latent heat.

Based on this definition, the terrestrial leg highlights transition zones between dry and wet climates, where the relationship between soil moisture and latent heat flux becomes significant. In this segment, strong coupling is obtained in regions where there is a good spread of soil moisture conditions, which drives the evapotranspiration dynamics. Conversely, dry and wet regions are smoothed by the index due either to the low soil moisture spread or to the poor relation between soil moisture and latent heat. Particularly, in dry regions, any increment in soil moisture causes a quick response in evapotranspiration, but soil moisture varies in a narrow range and the land-atmosphere interaction is not relevant. This feature is captured by a small soil moisture dispersion and the TCI is 
indicative of weak coupling. In wet regions the evapotranspiration depends more on the atmospheric demand than on the soil moisture availability. Then, the index value is small as a result of the low slope in the soil moisture-latent heat relationship. The atmospheric leg complements the terrestrial segment highlighting areas where latent heat fluxes impact precipitation. There are other, intermediate atmospheric variables, providing a stronger response to surface fluxes than precipitation, for instance, the height of the lifting condensation level (as used in Dirmeyer et al. 2014). However, in lack of data to compute such intermediate variables, we use precipitation, which is likely to dampen the importance of the atmospheric leg, yet is a strong indicator of the direct feedback from the atmosphere to the land completing the full cycle of land-atmosphere coupling. Thus, a zone where both legs are strong can be defined as a coupling hot spot where soil moisture anomalies are able to drive precipitation.

The coupling metrics are computed for the simulations presented in Table 1 using the following technical setup:

- Seasonal quantification of the index (MAM, JJA, SON, DJF) based on monthly data for the period 1950-2014.

- For soil moisture, the top three layers of each model are used, to account for water content availability for evaporation (first layer), but also for transpiration (second and third layers). The total value of soil moisture is calculated as a weighted average, where the weights are defined by the layer thickness.

- The soil layers thickness slightly varies from model to model: for HadGEM3.1, EC-Earth3 and ECMWF-IFS the top three layers depth is $1.0 \mathrm{~m}$, for MPI-ESM-1-2 the depth is $1.24 \mathrm{~m}$ (see Table 1). The selected soil moisture (SM) unit for the metric is volumetric water content $\left(\mathrm{m}^{3} \mathrm{~m}^{-3}\right)$ to avoid discrepancies caused by differences in soil-layer thickness among models.

- As showed in Eqs. (1) and (2), the coupling indices are statistical diagnostics and all general caveats related to significance apply. Consequently, grid points where the soil moisture-flux or flux-precipitation correlation have a confidence level $<99 \%$ were masked out.

\section{e. Process-based assessment}

The characterization of land-atmosphere coupling strength through coupling indices (TCI, ACI) is not a goal in itself, but rather a tool to identify regions sensitive to changes in resolution and/or sea surface temperatures. Then, a thoroughly step by step assessment is done to understand the dynamical processes within the land surface and in the atmosphere, treated together, that explain the TCI and ACI changes. An evaluation of the low- and highresolution GCMs performance in the simulation key climate variables related to land-atmosphere coupling complements the analysis. Process-based assessments are ideally suited to be carried out with sensitivity experiments using freely running GCMs, which is made possible by the coordinated experiments in HighResMIP. This approach complements previous studies using observations and/or reanalyses (e.g., Wei and Dirmeyer 2012, 2019), enabling us to critically assess the robustness of the uncovered mechanisms in CMIP6 GCMs, which are frequently used by the scientific community for climate predictions, including downscaling.

\section{f. Notes about the calculation of atmospheric moisture fluxes}

Moisture flux convergence is one of the key diagnostics considered in the process-based assessment. The calculation of moisture fluxes, as well as its comparison at different resolution, are not trivial tasks for HighResMIP simulations. The main technical caveats, and how they are resolved on this research to get reliable values of moisture flux convergence, are as follows:

- Pressure levels: The number of stored pressure levels is $\sim 10 \%$ of the model levels (see Table 1 ). The missing levels lead to biases in vertically integrated moisture flux convergence that produce a residual in the atmospheric water balance. The more pressure levels in the lower troposphere are used, the more accurate the calculations will be. To minimize the impact of missing levels we found that the inclusion of the surface pressure in the vertical integration of moisture fluxes is key to reducing the residual.

- Regridding: The comparison between fields of moisture fluxes and/or its convergence at different resolution implies a regridding step. It can be done on the original fields (winds and specific humidity) or directly over the moisture fluxes once they are calculated. It is particularly sensitive over land, where the orography produces noisy moisture fluxes near surface. We explored both alternatives and conclude that the best alternative is to regrid from high to low resolution after calculation of moisture fluxes using bilinear interpolation.

- Ostrograski-Gauss theorem: Given a box, the line integral of the flux on borders should be equal to the total moisture flux convergence inside the box. The best approximation to this equality is achieved by calculating (i) the weighted sum of moisture flux convergence in all grid cells inside the box, being the area of each grid cell the weight; (ii) for each border the mean flux between the inner and outer grid cell and multiplying by the length of the border, and then determining the net flux as the sum of the difference between east and west zonal fluxes and between north and south meridional fluxes. In steps $\mathrm{i}$ and ii, the final units are kilograms per second $\left(\mathrm{kg} \mathrm{s}^{-1}\right)$.

- Atmospheric water balance: The moisture flux convergence is balanced by the difference between evaporation and precipitation minus the variation in time of precipitable water. The technical caveats noted above prevent an exact comparison over a given box over land: 1) the vertical levels used in our calculations are not exactly the same as those used in the simulations; 2) the box limits may vary with resolution (grid points do not lie exactly on box boundaries), and this particularly affects borders lying over complex orography; and 3) the changes in precipitable water are not included in our calculations. However, we compare our calculations with the vertically integrated moisture fluxes provided only by HadGEM3 and verified the correct water budget closure over ocean boxes; also, a good agreement in the signs of moisture fluxes changes when two simulations at different resolutions are compared. 
(a) AMIP LR

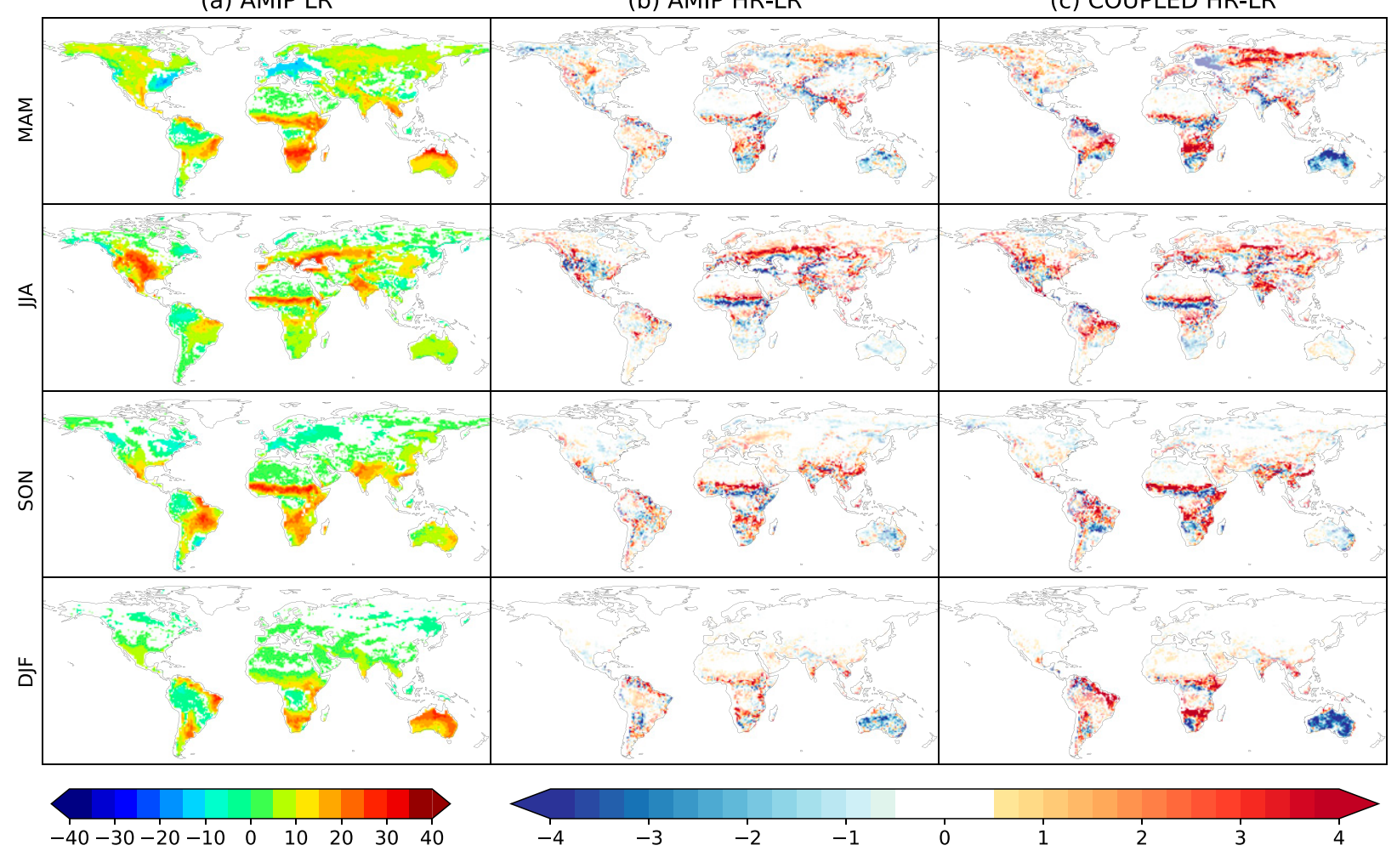

FIG. 1. (a) Multimodel mean seasonal TCI for AMIP-type simulations at low resolution and (b) their differences with high-resolution simulations. (c) As in (b), but for coupled simulations. Grid cells where the correlation between soil moisture and latent heat are not significant at the $99 \%$ confidence level are masked out in (a). Opacity is used in (b) and (c) to highlight regions of high TCI (TCI > $\left.10 \mathrm{~W} \mathrm{~m}^{-2}\right)$.

\section{Multimodel land-atmosphere coupling strength}

The coupling indices are applied for each model simulation described in section $2 b$. The seasonal multimodel ensemble means of each coupling segment for low-resolution AMIP simulations are presented in Fig. 1a for TCI and Fig. 2a for ACI. The hot spots of land-atmosphere coupling where the soil moisture state drives precipitation through latent heat are those with high TCI and ACI values. The main hot spots for each season are as follows:

- MAM: Brazilian savannah, Sahel, southern Africa.

- JJA: Sahel, India.

- SON: Brazilian savannah, Sahel, southern Africa, India.

- DJF: southern Africa, northern Australia.

The GCMs present a complete coupling pathway in regions with semiarid climates, particularly those with hot semiarid climates between the tropics (see climate classification in Beck et al. 2018), where the soil moisture anomalies affect the surface fluxes to the overlying atmosphere, which in turn, influence atmospheric instability, cloud formation, and precipitation Dirmeyer et al. (2014). In nonsemiarid areas, the terrestrial leg is weak because the soil is too dry and there is not enough water content for soil evaporation or plant transpiration, or else the soil is too wet and any increase in soil moisture does not produce significant changes in evapotranspiration. Extratropical regions with high TCI present positive latent heat-precipitation relationship, although much weaker than the soil moisture-latent heat pathway (e.g., western steppe of Eurasia and U.S. Great Plains in summer). In general, surface fluxes are sensitive to soil moisture when it varies in intermediate values (Guo and Dirmeyer 2013) given the predominant vertical interaction between the soil column and its surface. However, the moisture in the overlying atmosphere is exposed to complex processes (including synoptic systems) that may smooth the coupling signal evaluated in a single-column approach. For instance, for the Great Plains, Qiu and Williams (2020) found a strong response of convective clouds to evapotranspiration when the surface is wet and the atmosphere is more stratified and humid, conditions that are not present in all precipitation events. In terms of seasonality, the coupling takes place during the transition from dry to wet monsoon seasons. In these months, the monsoon circulations provide strong precipitation variability, enhancing the potential land-atmosphere interactions. Overall, the land-atmosphere coupling hot spots identified by the selected CMIP6 GCMs present a strong resemblance with those previously reported by Dirmeyer (2011) 
(a) AMIP LR

(b) AMIP HR-LR

(c) COUPLED HR-LR

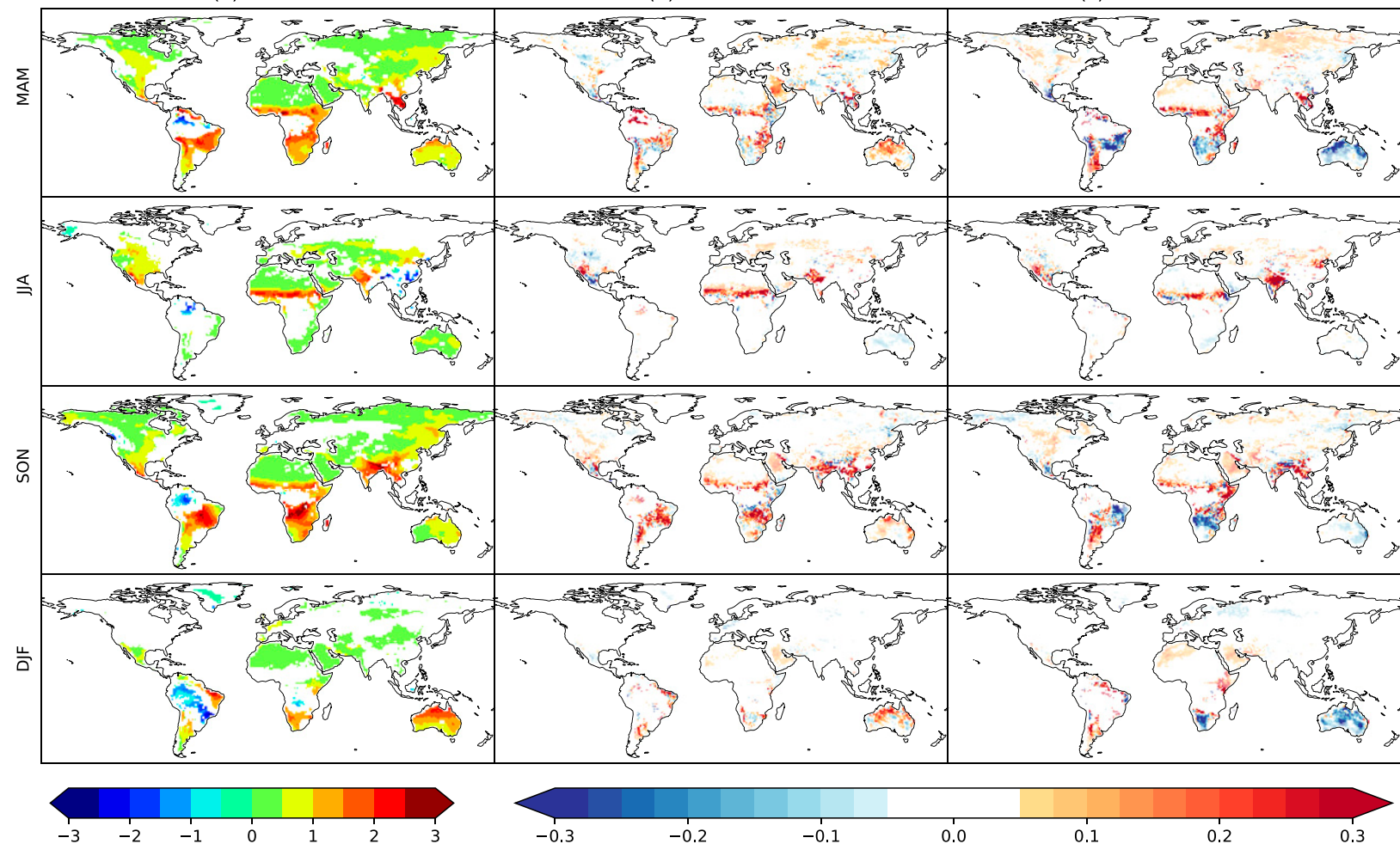

FIG. 2. As in Fig. 1, but for ACI. The threshold that defines the opacity is ACI $>1 \mathrm{~mm}^{-1}{ }^{-1}$.

using the same methodology and Koster et al. $(2004,2006)$ using the GLACE coupling strength $(\Delta \Omega)$, which relates soil moisture as a precursor of precipitation for boreal summer.

Figures 1 and 2 also present the multimodel ensemble mean differences produced by resolution (HR-LR) for AMIP (center column) and COUPLED (right column) simulations. The enhanced resolution produces both strengthening and weakening of coupling, although positive changes predominate in all seasons both in AMIP and COUPLED simulations. The coupling changes (either positive or negative) are more noticeable in those regions considered hot spots where TCI $>$ $10 \mathrm{~W} \mathrm{~m}^{-2}$ and ACI $>1 \mathrm{~mm} \mathrm{day}^{-1}$. Such sensitivity to resolution in TCI is mainly produced by the alteration of soil moisture availability and variability that alter surface fluxes leading to changes in ACI. A general explanation is that the increased resolution in models modifies the large-scale circulation producing different precipitation patterns (Demory et al. 2014), for example, increasing orographic precipitation (Vannière et al. 2019), but also modifying the precipitation timing (e.g., the snow onset and melt; Brutel-Vuilmet et al. 2013). These effects are even larger in COUPLED simulations (e.g., Brazil, Australia during austral summer and autumn) as the inclusion of the ocean magnifies the differences in atmospheric moisture fluxes between resolutions. However, each region should be explored separately to understand the processes involved in the land-atmosphere coupling changes. In this work, the Sahel hot spot is explored to understand the expansion to the north in the coupling at high resolution that leads to a dipole in TCI, that is, reduced terrestrial coupling to the south and enhanced coupling to the north, and an intensification of ACI in northern Sahel. Although there are other regions with strong differences, we decided to focus our analysis on the Sahel hot spot because 1) it is produced by all GCMs in both AMIP and COUPLED simulations, 2) it covers two seasons starting in JJA and persisting until SON, and 3) it is a region of increasing scientific interest in environmental and social sciences that spans over 7 million $\mathrm{km}^{2}$ and has close to 135 million inhabitants.

\section{Resolution effects on the Sahel hot spot}

\section{a. Analysis of involved processes}

The Sahel is a region influenced by very particular meteorological features like African easterly waves, the African easterly jet, the intertropical convergence zone, and the West African monsoon, and it is the place where the genesis of Atlantic tropical cyclones occurs. Concequently, it is essential to consider all of these phenomena in the understanding of the land-atmosphere interplay and its sensitivity to resolution. Figure 3 shows a zoom over the Sahel hot spot including the differences caused by resolution in TCI and ACI, but also in a set of atmospheric and surface variables that allows a plausible explanation of the coupling changes observed in high-resolution models. 

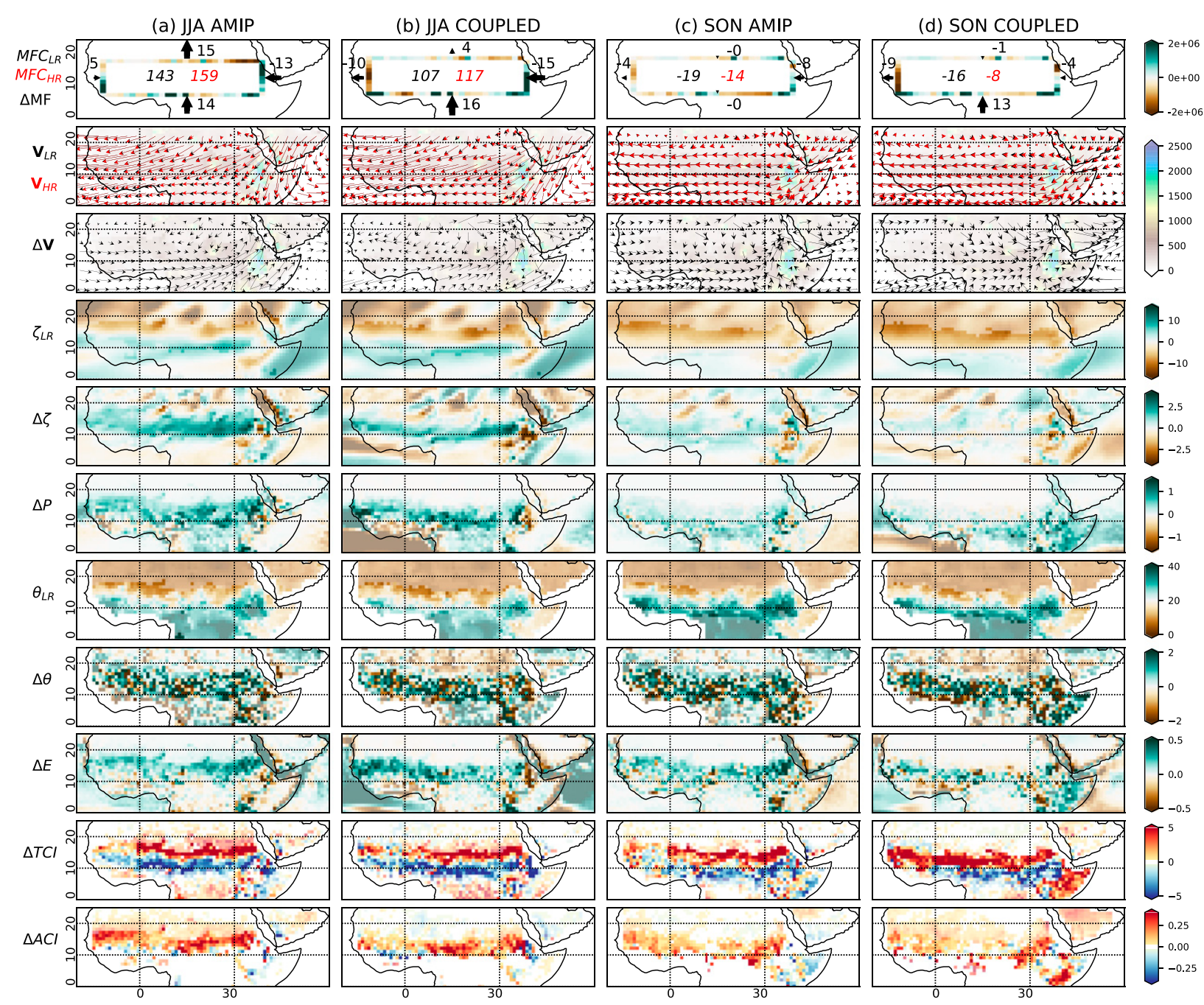

FIG. 3. Differences in atmospheric and soil variables and TCI over the Sahel hot spot caused by changes in GCMs resolution during summer for (a) AMIP-type and (b) COUPLED simulations; (c),(d) as in (a) and (b), but for autumn. Opacity was used in all panels to highlight regions of high TCI (TCI $>10 \mathrm{~W} \mathrm{~m}^{-2}$ ). The rows from top to bottom are as follows: volume integral of moisture flux convergence, $\mathrm{MFC}=P-E(\mathrm{LR}$ and $\mathrm{HR})\left(10^{6} \mathrm{~kg} \mathrm{~s}^{-1}\right)$, in the center of the box and vertically integrated moisture flux (MF) (LR and HR) along box sides $\left(10^{6} \mathrm{~kg} \mathrm{~s}^{-1}\right)$, being positive for eastward and northward flow differences; winds $\mathbf{V}$ at $600 \mathrm{hPa}(\mathrm{LR}$ and $\mathrm{HR})\left(\mathrm{m} \mathrm{s}{ }^{-1}\right)$ over orography (m MSL); winds at $600 \mathrm{hPa}(\mathrm{HR}-\mathrm{LR})\left(\mathrm{m} \mathrm{s}^{-1}\right)$ over orography (m MSL); relative vorticity $\zeta$ (LR) and (HR-LR) $\left(10^{-6} \mathrm{~s}^{-1}\right)$; precipitation $P\left(\right.$ HR-LR) $\left(\mathrm{mm} \mathrm{day}^{-1}\right)$; top three layers soil moisture $\theta(\mathrm{LR})\left(\mathrm{m}^{3} \mathrm{~m}^{-3}\right)$; top three layers soil moisture $(\mathrm{HR}-\mathrm{LR})\left(\mathrm{m}^{3} \mathrm{~m}^{-3}\right)$; evapotranspiration $E$ (HR-LR); and TCI $\left(\mathrm{W} \mathrm{m}^{-2}\right)$.

The northward shift in TCI starts in boreal summer (Fig. 3, left columns), due to changes in the atmospheric conditions. The moisture flux from the Indian Ocean is notably increased at high resolution in both AMIP and COUPLED (Fig. 3, see green borders of the box at southeast). Part of the extra moisture from the east escapes through the northeast (see brown borders) due to an intensification of anticyclonic circulation, as shown by $\zeta_{\mathrm{LR}}$ and $\Delta \zeta$ in that area. However, the rest of atmospheric moisture remains in the region, mainly in AMIP, which presents a reduction of zonal moisture flux from the Sahel to the Atlantic Ocean, leading to an overall increase of atmospheric moisture in the box of $21 \%$ (from $132 \times 10^{6}$ to $160 \times 10^{6} \mathrm{~kg} \mathrm{~s}^{-1}$ ). In COUPLED ensemble there is higher loss of moisture in western Sahel at high resolution, but the net difference between gains and losses remains positive by a magnitude of about $10 \%$ (from $107 \times 10^{6}$ to $117 \times 10^{6} \mathrm{~kg} \mathrm{~s}^{-1}$ ). This increment of atmospheric moisture comes with changes in circulation. The sharp gradients of the mountains in the Horn of Africa (Fig. 3, blue-green shades in second row) are better defined at high resolution (see section 4.1.2 in Johnson et al. 2016) and modify the African easterly jet. There is a strong decrease of easterlies south of $\sim 13^{\circ} \mathrm{N}$ and, on the other hand, a slight increase north of $\sim 13^{\circ} \mathrm{N}$, leading to a stronger background horizontal wind shear. The changes in the jet cause an increase of relative vorticity over the domain. It is striking to see that regions of enhanced relative vorticity remarkably 
(a) SM and P annual cycle

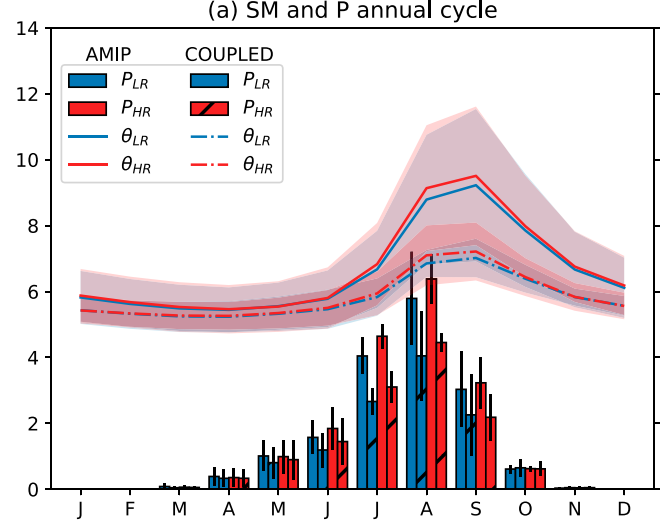

(b) Lagged correlation between SM and P

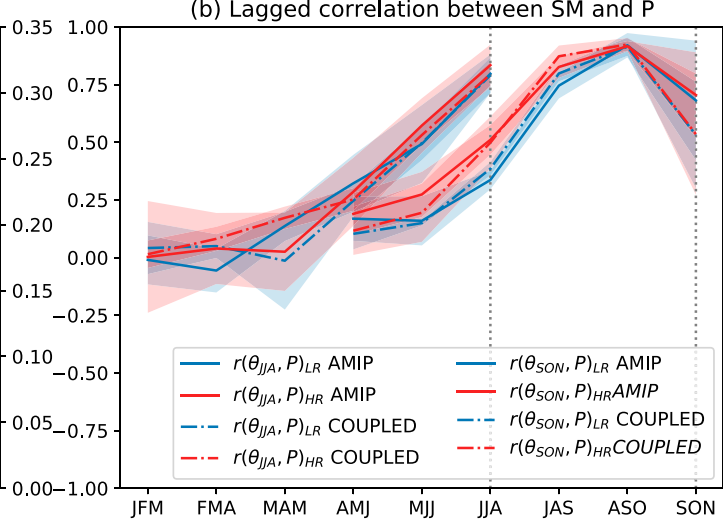

FIG. 4. Areal averaged precipitation and soil moisture in the box $10^{\circ}-15^{\circ} \mathrm{N}, 0^{\circ}-30^{\circ} \mathrm{E}$. (a) Mean annual cycle of precipitation $\left(\mathrm{mm} \mathrm{day}^{-1}\right)$ (left axis) and soil moisture $\left(\mathrm{m}^{3} \mathrm{~m}^{-3}\right)$ (right axis). The bars and curves show the multimodel ensemble mean for AMIP-type (solid blue and red for LR and HR, respectively) and COUPLED simulations (dashed blue and red for LR and HR, respectively), while error bars and shades show the respective ensemble standard deviation. (b) Correlation between seasonal soil moisture (JJA and SON) and lagged trimonthly precipitation.

coincide with regions of enhanced precipitation. A simple explanation is that the increase of the background relative vorticity corresponds to favorable conditions for the development of AEWs. Indeed, AEWs are generated by combined barotropic and baroclinic instability of the African easterly jet. Barotropic instability arises in regions of large horizontal wind shear. We find that the horizontal shear (more precisely the meridional gradient of the zonal wind) is enhanced at higher resolution, which is characterized by larger relative vorticity in a region already prone to barotropic instability. As a result, more African easterly waves are generated (Vellinga et al. 2016) and more moisture is brought into the domain by their embedded mesoscale convective systems.

The enhanced instability favors precipitation events and, thereby, wetter soil conditions. This process 1) boosts the evapotranspiration where the soil was dry at low resolution, enhancing the complete coupling pathway above $\sim 13^{\circ} \mathrm{N}$, and 2) produces more runoff (not shown) where the soil was already wet at low resolution, reducing the terrestrial coupling below $\sim 13^{\circ} \mathrm{N}$. Note that soil moisture panels present an overall wetter state, but with scattered patches depicting negative differences. That is a direct effect of the increase in models' resolution, which augments the spatial variability of soil and land-cover types and their related properties (e.g., soil hydraulic conductivity, soil porosity, stomatal resistance, among others) producing different spatial responses to a similar increase in rain. For instance, a grid cell prescribing a higher content of sand and/or denser vegetation at high resolution, is not able to store the extra precipitation in the soil column as it is lost by drainage or retained by the canopy. Moreover, the spatial heterogeneity of soil moisture fields is inherent to most land surface models, as they follow a single-column approach, unlike the three-dimensional nature of atmospheric models.

In the boreal autumn (right columns) the TCI shift bears a notable resemblance to that observed in the previous season; however, the changes in coupling are triggered by soil conditions rather than atmospheric conditions. The top panels show that moisture flux convergence is very low in SON, with similar values at both resolutions. Moreover, the slight increase in relative vorticity and precipitation in the ensemble mean is strongly influenced by HadGEM3, a model that presents similar processes sensitivity to resolution in summer and autumn (further details in section $4 \mathrm{~b}$ ). In other models, the increase of moisture convergence, relative vorticity and rain at high resolution is minimum during autumn. The extra rain in HadGEM3 explains in part the positive differences in soil moisture. However, wetter soils are mostly explained by the storage of moisture from the previous season, the so-called soil memory effect (Koster and Suarez 2001; Wu and Dickinson 2004; Seneviratne et al. 2006). The lagged effect of precipitation is clearly visible in Fig. 4a, which shows the maximum soil moisture in September, one month after the rainy season. Moreover, the right panel (Fig. 4b) shows that summer soil moisture is well correlated with summer precipitation, while autumn soil moisture is highly correlated with precipitation in JAS and ASO, demonstrating how the soil "remembers" the wet atmospheric conditions in previous months. Now that we have interpreted the role of soil memory in autumn, we go back to the interpretation of spatial changes in land-atmosphere coupling during that season, which is the same as in JJA for the terrestrial leg but not for the atmospheric leg. To the north, soils tend to be wetter in the high-resolution models, leading to stronger coupling between soil moisture and evapotranspiration. However, this extra surface moisture flux is not enough to produce more rain by itself, which highlights the primary role of atmospheric moisture fluxes in producing suitable conditions for rain (as it occurs with HadGEM3, see section 4b). To the south, the extra water in already wet soils does not affect the soil dynamics and only produce more runoff, thus capping the ability of soil moisture to alter the overlying atmosphere.

Focusing on how GCM resolution affects the terms and variables involved in the construction of the terrestrial 

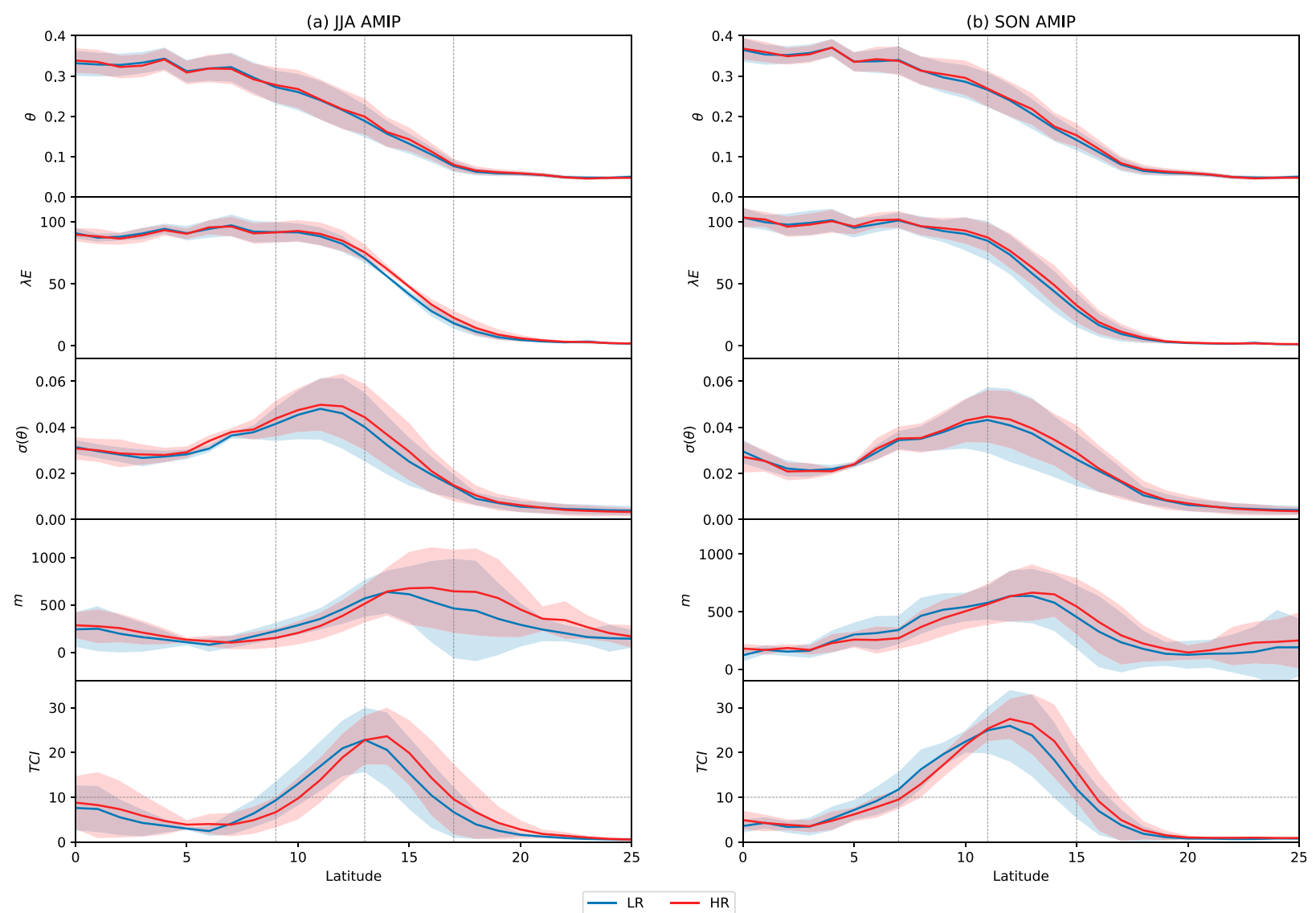

FIG. 5. Zonal average $\left(12^{\circ} \mathrm{W}-38^{\circ} \mathrm{E}\right)$ for LR (blue) and HR (red) of soil moisture $\theta$, latent heat $\lambda E$, standard deviation of soil moisture $\sigma(\theta)$, slope $m$ of the relationship between soil moisture and latent heat and TCI for AMIP simulations in (a) JJA and (b) SON. Solid lines are multimodel means and shades multimodel dispersion. The vertical lines are a reference to facilitate the identification of the Sahel land-atmosphere coupling hot spot in summer and autumn.

coupling index, Fig. 5 shows that the shift in TCI is driven by a similar shift in the slope of regression between soil moisture and latent heat $(m)$. In JJA there is a slight increase in soil moisture and its variability at $\mathrm{HR}$ from $9^{\circ}$ to $17^{\circ} \mathrm{N}$, leading to enhanced latent heat. However, the LR and HR slopes present different behaviors south and north of $13^{\circ} \mathrm{N}$. From $9^{\circ}$ to $13^{\circ} \mathrm{N}$ the HR slope remains under the LR slope because the soil moisture at HR is closer or over the field capacity more frequently than soil moisture at LR. This 1) makes evaporation dependent on atmospheric demand and 2) limits the transpiration, as the excess of water in the root zone cannot be held by plants against gravitational drainage (Seneviratne et al. 2010). Then, latent heat does not vary as much as the soil moisture reducing the slope. From $13^{\circ}$ to $17^{\circ} \mathrm{N}$ the Sahel is drier and any rise in soil water availability produces a quick response in latent heat, and a steeper slope $m$. A similar explanation applies to SON, but the hot spot is located about $2^{\circ}$ farther south compared to the previous season. It responds to a seasonal variation in the location of the intertropical convergence zone, which moves south in the transition from summer to winter (Chiang et al. 2002).

In other words, the high-resolution GCMs show changes in the evaporative regimes (see regimes classifications in Koster et al. 2009). This is clearly shown for example, in Figs. 6a and 6b for ECMWF-IFS AMIP-type simulations. The high-resolution simulation presents in JJA and SON a rise in soil water availability $\beta$ at all latitudes of the Sahel belt. As we move from the north to the break latitude $\left(13^{\circ} \mathrm{N}\right.$ in JJA and $12^{\circ} \mathrm{N}$ in SON), latent heat variability responds positively to the wetter soil condition, that is, the evaporative regime remains controlled by soil moisture in both resolutions. However, from the break latitude toward the equator the evaporative regime slightly transitions from soil moisture limited at low resolution to energy controlled at high resolution. That is, high-resolution simulation reaches an energy limited regime slightly more north than lowresolution does. The explanation is that at low latitudes there is a surplus of soil moisture and energy that keeps the stomata fully opened and the evapotranspiration near maximum. It is well known that above a certain level (usually called soil moisture critical point) the evapotranspiration is insensitive to soil moisture variations and the evaporative fraction becomes essentially constant [see section 4.1 in Seneviratne et al. (2010) and references therein]. The way in which the evaporative regimes respond to the degree of saturation is clearly captured by the terrestrial coupling index in Fig. 6c for JJA and Fig. 6d for SON. 
(a) JJA ECMWF-IFS AMIP

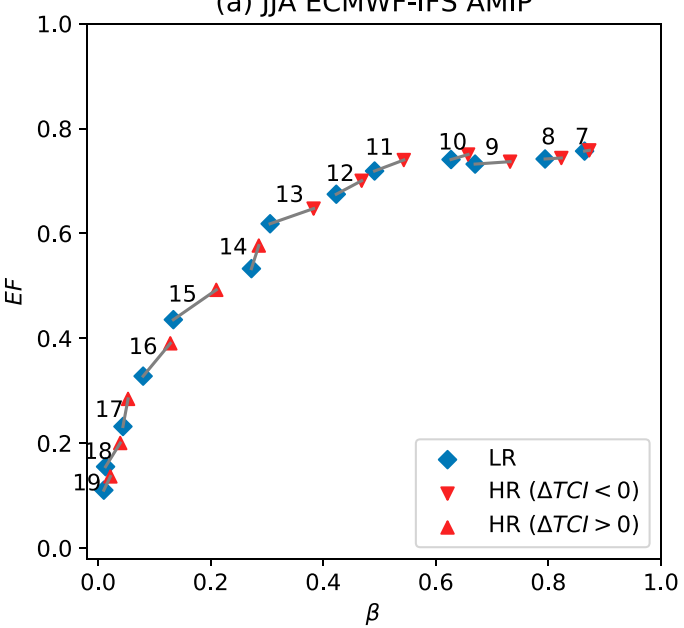

(c) JJA ECMWF-IFS AMIP

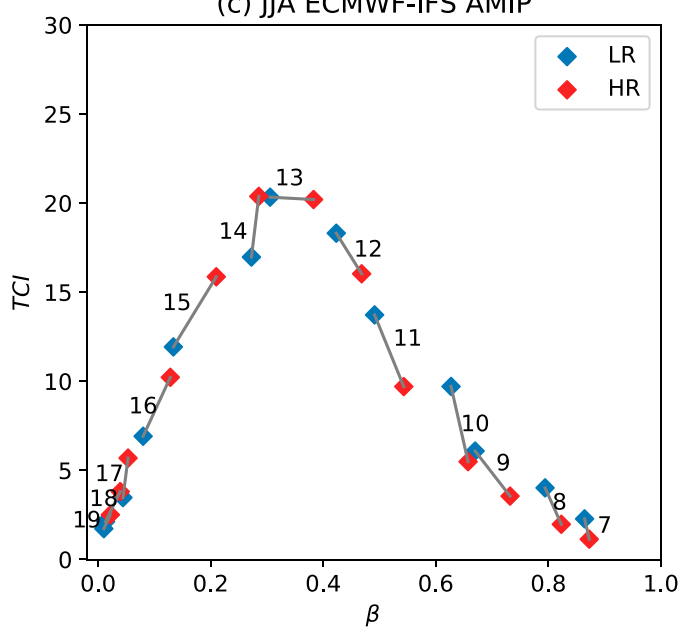

(b) SON ECMWF-IFS AMIP

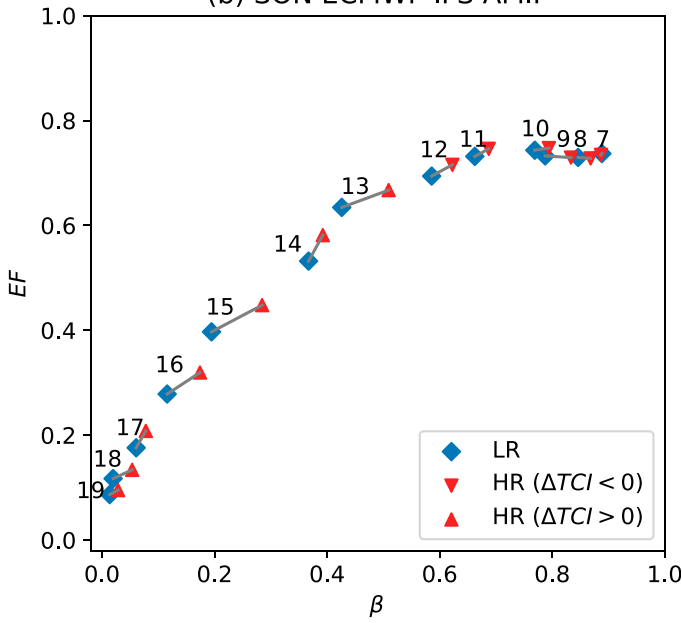

(d) SON ECMWF-IFS AMIP

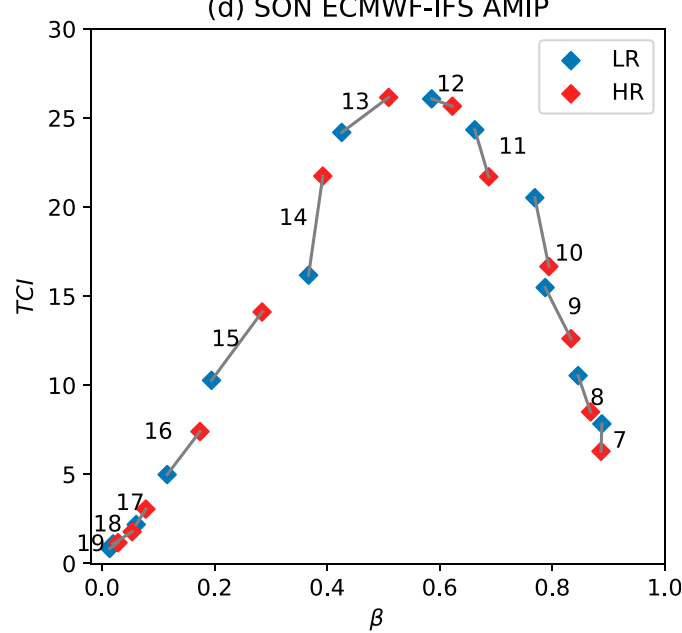

FIG. 6. (a) JJA and (b) SON evaporative regimes at low and high resolution. The markers show the zonal average $\left(12^{\circ} \mathrm{W}-38^{\circ} \mathrm{E}\right)$ for LR (blue) and HR (red) of soil moisture availability $\beta=\left(\theta-\theta_{\mathrm{wp}}\right) /\left(\theta_{\mathrm{fc}}-\theta_{\mathrm{wp}}\right)$ vs evaporative fraction $\mathrm{EF}=\lambda E /(\lambda E+\mathrm{SH})$ for ECMWF-IFS AMIP simulations. (c) JJA and (d) SON TCI as function of soil moisture availability. Gray segments match equivalent latitudes in low- and high-resolution simulations. The numbers indicate the respective latitudes.

At high resolution, the coupling is stronger when the evapotranspiration is controlled by the soil moisture content and is weaker when the evapotranspiration depends on the atmospheric demand, rather than on the land state.

It is interesting to note in Fig. 6 that the resolution comparison shows a change in the regime but retains the physical relationship between soil moisture availability and evaporative fraction over a consistent regression. It demonstrates that the wetter atmospheric conditions do not alter the physical behavior of the system; they just change the soil state, causing shifts in the evaporative regimes.

\section{b. Multimodel agreement}

So far, we have seen the resolution effects on the Sahel landatmosphere coupling based on multimodel ensemble mean and dispersion (e.g., bottom panels of Fig. 5). Figures 7a and $7 \mathrm{~b}$ present the terrestrial and atmospheric coupling differences between highand low-resolution for each member of the AMIP and COUPLED ensembles in JJA and SON. The multimodel agreement in the northward shift of the terrestrial leg at high resolution is remarkable. The dipole is present in six out of seven GCMs in both seasons. The exception is given by the MPI-ESM COUPLED model, which is dominated by a reduction of coupling in the whole region in summer and scattered positive and negative differences in autumn. In JJA, this model shows drier atmospheric conditions at high resolution with reduced moisture flux convergence and precipitation (Fig. 7c). This leads to a drier soil and diminishes the evapotranspiration. In summary, there is a negative feedback in the water balance that smooths the land-atmosphere coupling. Given the drier winter at high resolution, the SON rainfall events play a more active role in autumn terrestrial coupling. For instance, the intensification of TCI in the Horn of Africa directly 


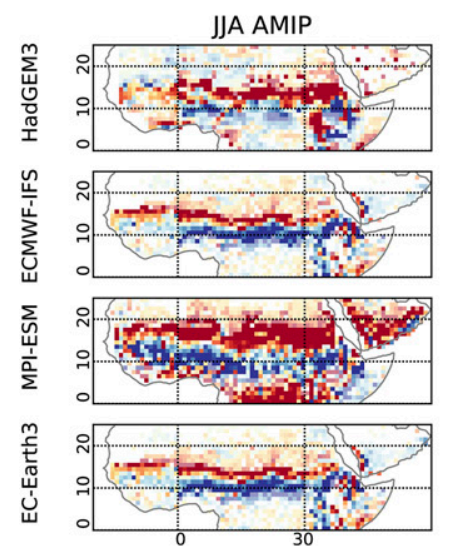

(a) Multi-model TCl difference (HR-LR) (1950-2014)
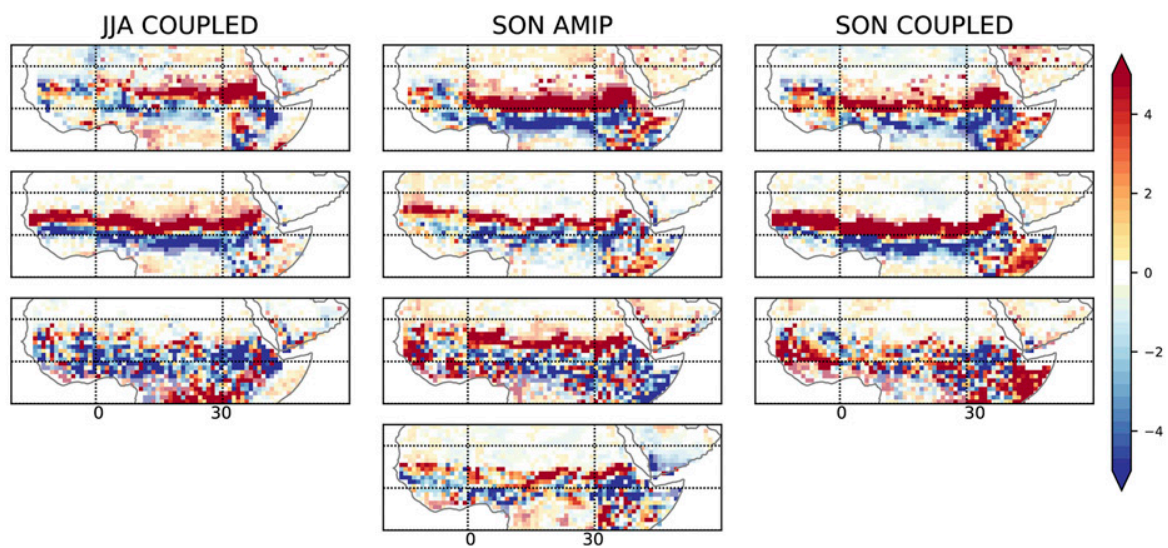

(b) Multi-model ACl difference (HR-LR) (1950-2014)
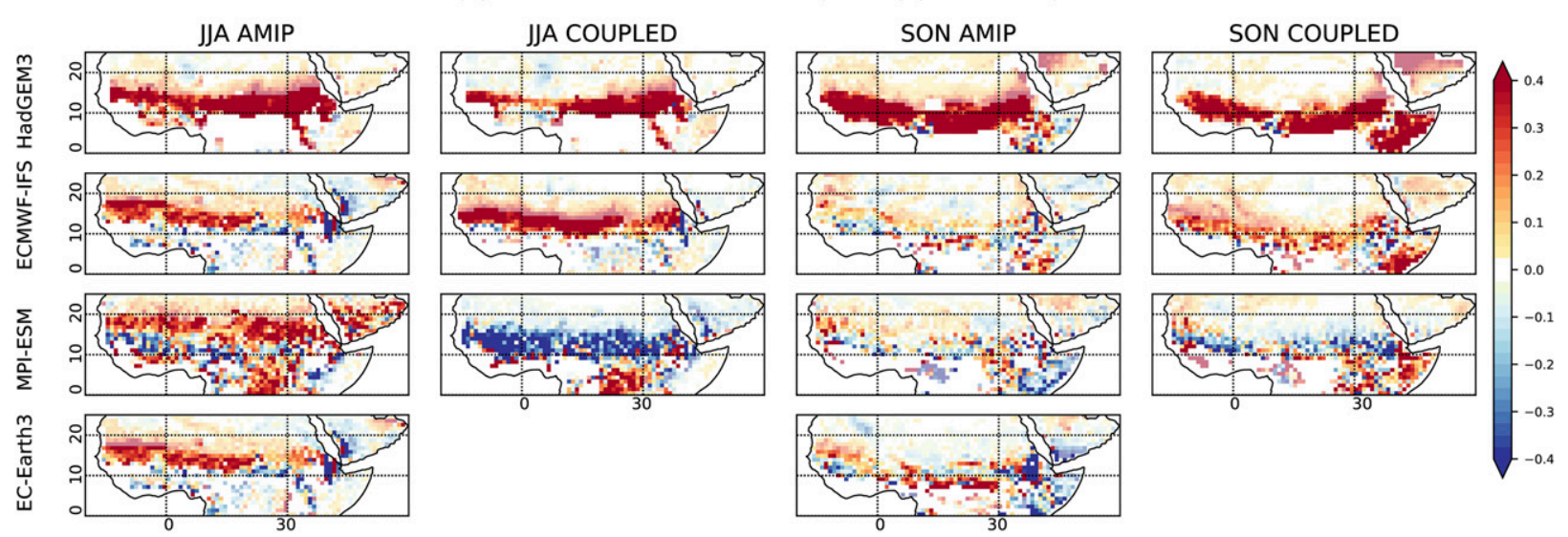

(c) MPI-ESM COUPLED
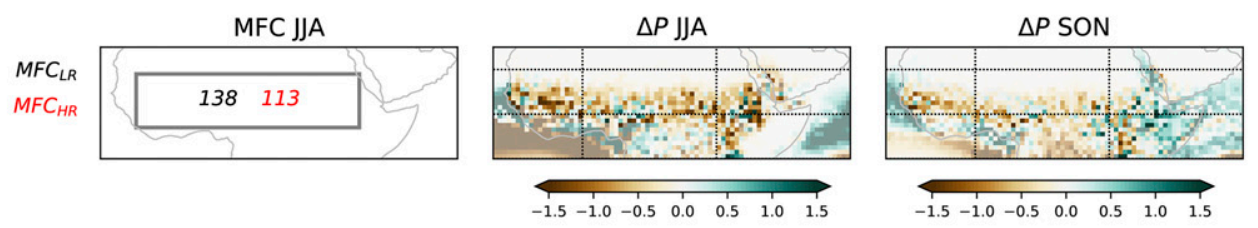

(d) HadGEM3 AMIP
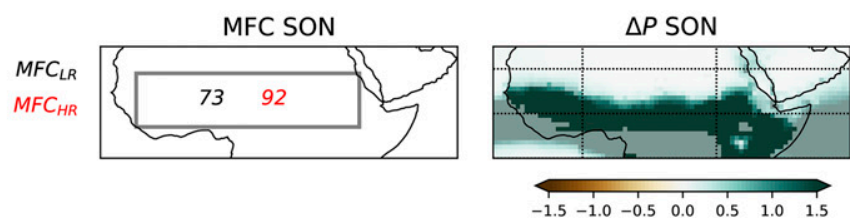

FIG. 7. (a),(b) Differences in average TCI and ACI for individual GCMs over the Sahel caused by changes in horizontal resolution during summer and autumn for AMIP-type and COUPLED simulations. Opacity was used in all panels to highlight regions of high ensemble mean TCI (TCI $>10 \mathrm{~W} \mathrm{~m}^{-2}$ ) in (a) and high ensemble mean ACI (ACI $>1 \mathrm{~mm} \mathrm{day}^{-1}$ ) in (b). (c) Analysis of MPI-ESM COUPLED TCI differences with volume integral of moisture flux convergence $\left(10^{6} \mathrm{~kg} \mathrm{~s}^{-1}\right)$ in (left) summer and precipitation differences $\left(\mathrm{mm} \mathrm{day}^{-1}\right.$ ) in (center) summer and (right) autumn. (d) As in (c), but for HadGEM3 AMIP in SON to explain ACI differences.

responds to a rise in autumn precipitation with a rapid wetting of soil and increase in latent heat.

The multimodel agreement is also evident for ACI (Fig. 7b), mainly in JJA where all models, except the noted MPI-ESM COUPLED case, present a strengthening of the link between latent heat and precipitation at high resolution in northern Sahel and small (and spatially mixed) positive and negative differences or even nonsignificant correlations in southern Sahel. In SON, all models except HadGEM3 and MPI-ESM COUPLED present small positive changes when the resolution is increased, 

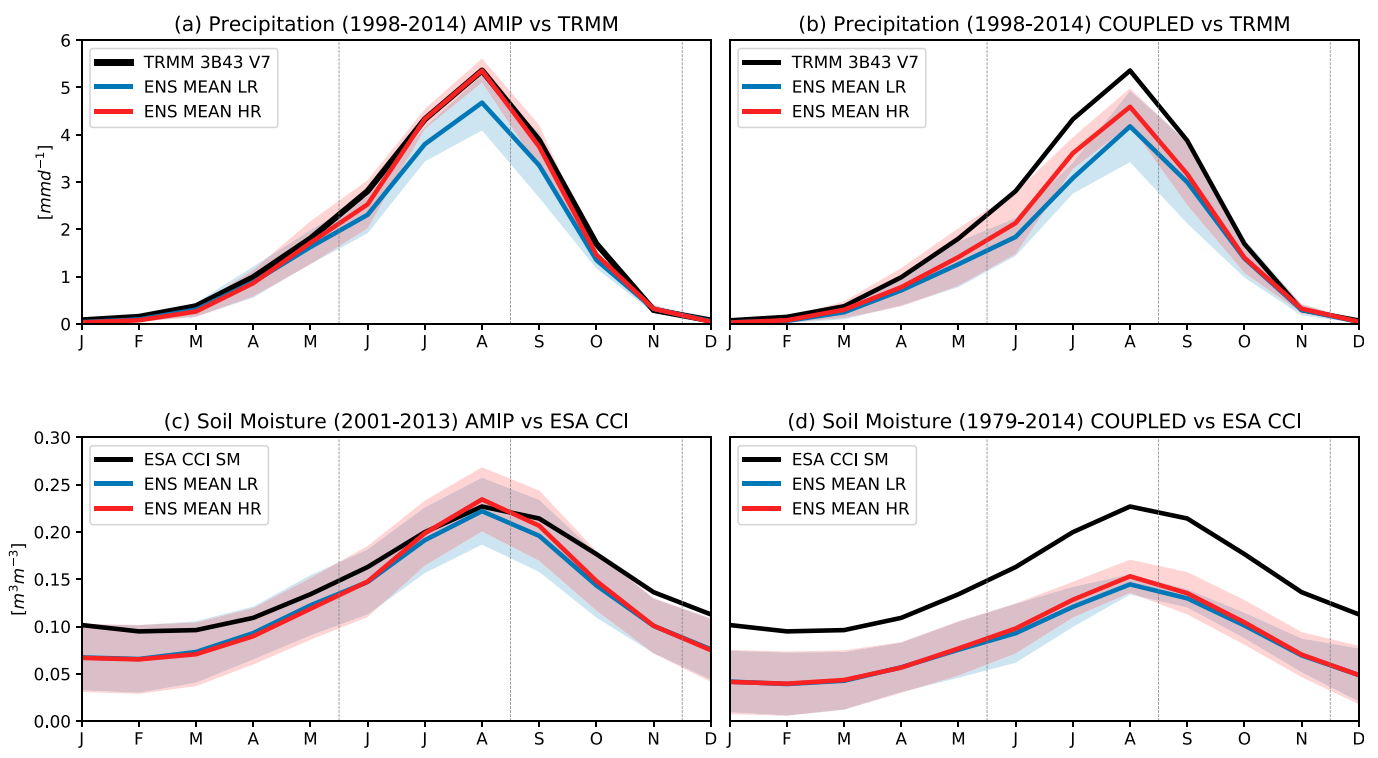

(d) Soil Moisture (1979-2014) COUPLED vs ESA CCI

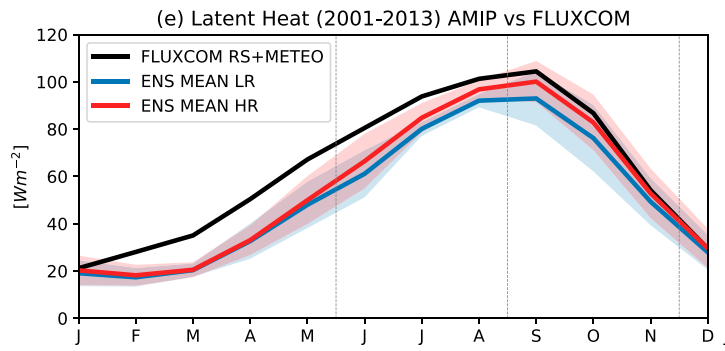
(f) Latent Heat (2001-2013) COUPLED vs FLUXCOM

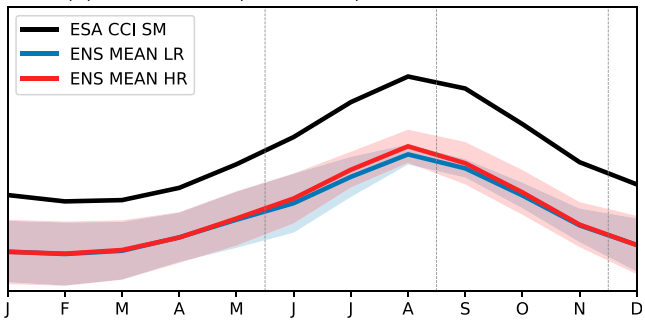

(f) Latent Heat (2001

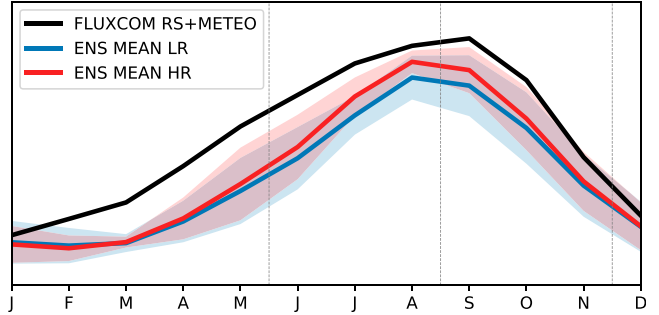

FIG. 8. Annual cycle of (a),(b) precipitation, (c),(d) soil moisture, and (e),(f) latent heat for the Sahel (delimited by $7^{\circ}-19^{\circ} \mathrm{N}$ and $12^{\circ} \mathrm{W}-38^{\circ} \mathrm{E}$ ) for remotely sensed data and LR and HR multimodel ensembles mean (solid lines) and models dispersion (shaded bands). Panels (a), (c), and (e) compare AMIP simulations against remote sensed data, while (b), (d), and (f) are the same, but for COUPLED simulations. The vertical lines are a reference to facilitate the identification of the seasons of interest.

suggesting that the wetter soil conditions are able to drive changes in evapotranspiration, but this is not a sufficient condition to affect precipitation. Only when the extra soil moisture is combined with extra moisture fluxes, as shown in JJA by most models or in SON by HadGEM3, the complete land-atmosphere pathway takes place. In particular, HadGEM3 strengthens the atmospheric leg in SON due to an increase of $26 \%$ in moisture flux convergence, which favors the development of rain (Fig. 7d), moistening the soil, which in turn produces more evapotranspiration (if the evaporative regime is controlled by soil moisture) adding more moisture to that provided by remote sources to produce more rain. Note that HadGEM3 is the model with the largest change in resolution (Table 1), a feature that explains the remarkable increase in moisture fluxes and rain in SON. In other models, the increase of moisture convergence at high resolution is minimum during autumn, thus the sensitivity of the terrestrial leg to resolution remains the same than in JJA due to soil memory, but the increase in evapotranspiration does not have a major effect on precipitation, and thereby, the sensitivity of the atmospheric leg to resolution is negligible.

\section{c. Assessment of key variables with remotely sensed data}

We have uncovered how the increase in GCMs resolution alters land-atmosphere coupling processes in the Sahel. The question that naturally arises is, does the enhancement of a model's resolution offer a more realistic simulation of landatmosphere coupling processes? As discussed in section $2 \mathrm{c}$, we propose to address this question through an evaluation, with remotely sensed data, of the most relevant variables of the complete land-atmosphere coupling pathway.

Figure 8 contrasts the mean annual cycle of remotely sensed precipitation, soil moisture and evapotranspiration for Sahel with models' estimates. The curves of all model ensembles (AMIP LR, AMIP HR, COUPLED LR, and COUPLED HR) correctly reproduce the satellite estimates with maximum between the end of summer and the beginning of autumn, and minimum in winter. However, the wetter conditions at high resolution in summer and autumn systematically reduce the negative biases of LR ensembles (see Table 2). The resemblance of AMIP HR models precipitation with TRMM 3B43_V7 in 
TABLE 2. Mean ensemble percent biases in Sahel using TRMM 3B43_V7 as a reference for precipitation, ESA CCI SM v4.7 for soil moisture, and FLUXCOM RS + METEO for latent heat.

\begin{tabular}{|c|c|c|c|c|c|c|}
\hline \multirow[b]{2}{*}{ Ensemble } & \multicolumn{3}{|c|}{ JJA bias (\%) } & \multicolumn{3}{|c|}{ SON bias (\%) } \\
\hline & $P$ & $\theta$ & $\lambda E$ & $P$ & $\theta$ & $\lambda E$ \\
\hline AMIP LR & -13.5 & -5.1 & -15.3 & -14.4 & -16.5 & -11.0 \\
\hline AMIP HR & -1.9 & -1.5 & -10.0 & -5.6 & -13.6 & -3.9 \\
\hline COUPLED LR & -27.0 & -39.6 & -22.5 & -20.0 & -43.2 & -21.3 \\
\hline COUPLED LR & -17.1 & -36.0 & -15.5 & -16.4 & -41.5 & -16.3 \\
\hline
\end{tabular}

time (Fig. 8a) is remarkable, but also its latitudinal distribution over Sahel both in summer and autumn (Figs. 9a and 9c, respectively). As expected, ensembles based on COUPLED simulations present greater biases compared to AMIP (Figs. 8 and 9 and Table 2) given that sea surface temperatures are constrained in AMIP, while in the COUPLED configuration all GCMs components are freely running.

We have shown in section $4 \mathrm{~b}$ that MPI-ESM COUPLED does not respond to the same chain of processes identified in other GCMs when resolution is enhanced. A specific comparison (not shown) of JJA precipitation between the four MPI-ESM simulations (AMIP LR, AMIP HR, COUPLED LR, and COUPLED HR) and TRMM 3B43_V7 shows that the MPI-ESM GCM correctly identifies the latitudinal gradient in precipitation, although with a dominant dry bias. However, AMIP HR reduces the mean bias by about $43 \%$ (from $-17 \%$ to $-10 \%$ ) while COUPLED HR (the exception) increases it by about $10 \%$ (from $-20 \%$ to $-22 \%$ ). Therefore, the Sahel is a region where MPI-ESM underestimates the rain, and the increase of precipitation showed by the AMIP HR version of the model helps to reduce the negative bias and improve the simulation of land-atmosphere interactions. In the COUPLED mode (the
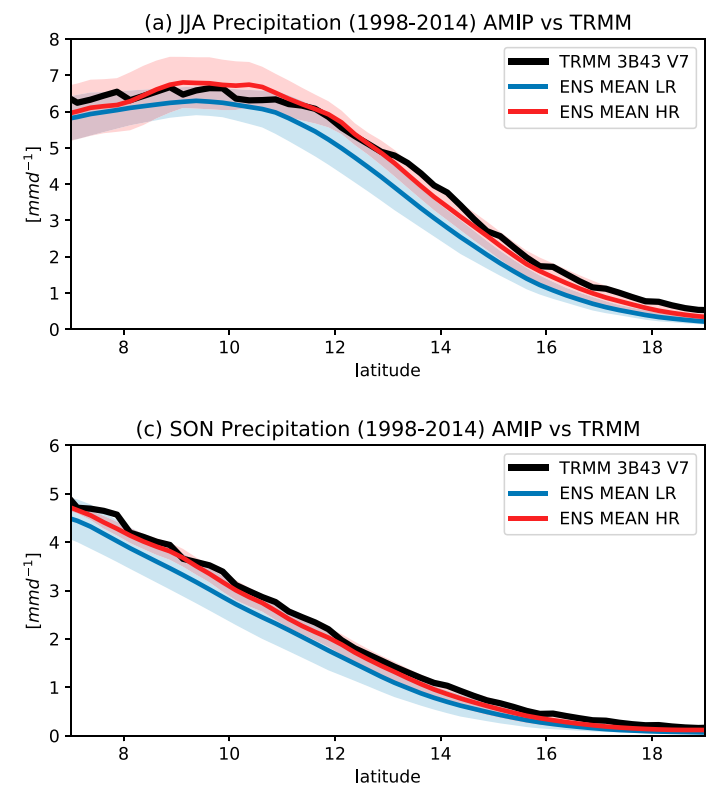

exception) the dry bias is even higher at high resolution, and therefore there is no relocation of the coupling hot spot.

The limitations of remotely sensed products to assess the simulations (e.g., short temporal coverage, missing data, the impossibility of measuring soil moisture in deep layers) do not allow to draw definitive conclusions. However, the results suggest that land-atmosphere coupling processes in Sahel are better simulated at high resolution, where models are able to accurately reproduce precipitation patterns during the rainy season (mainly AMIP), which in turn, produces more realistic soil conditions and surface fluxes expanding the coupling hot spot to the north.

\section{Discussion and concluding remarks}

In this study we have evaluated the sensitivity of landatmosphere coupling to GCM horizontal resolution in a set of 14 AMIP-type and COUPLED simulations submitted to CMIP6. The simulated period covers 1950-2014, and the model's resolution varies from $\sim 1^{\circ}$ to $\sim 0.25^{\circ}$ in average, for low- and high-resolution simulations, respectively. The landatmosphere strength is computed using a classic diagnostic that

\section{(b) JJA Precipitation (1998-2014) COUPLED vs TRMM}

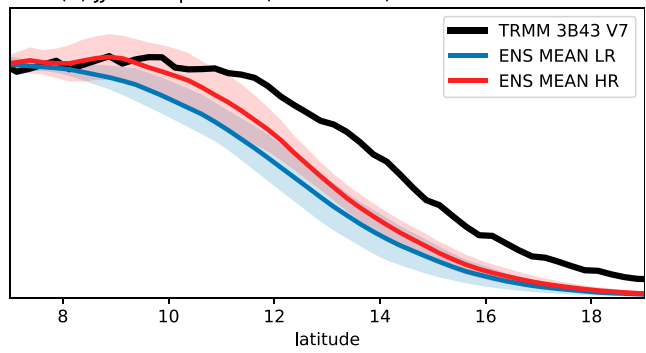

(d) SON Precipitation (1998-2014) COUPLED vS TRMM

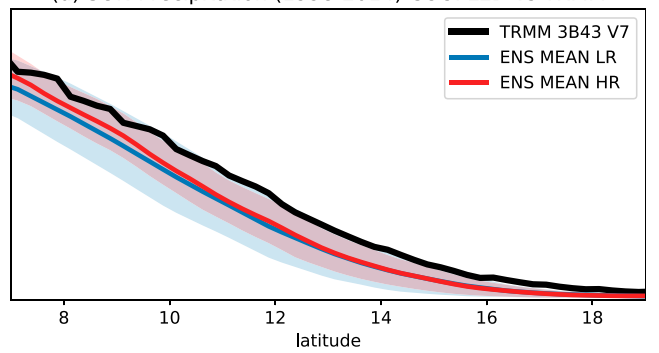

FIG. 9. Zonal average $\left(12^{\circ} \mathrm{W}-38^{\circ} \mathrm{E}\right)$ ensemble mean precipitation for (a) JJA AMIP, (b) JJA COUPLED, (c) SON AMIP, and (d) SON COUPLED. The corresponding TRMM 3B43_V7 curve is included in each panel as a reference. 
ATMOSPHERE

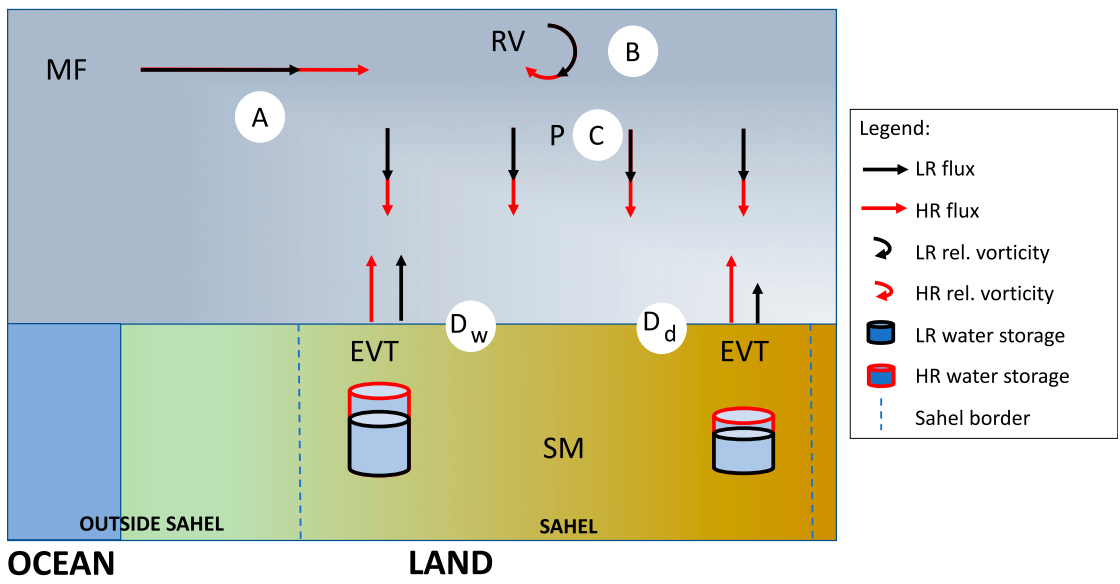

FIG. 10. Simplified schematic diagram of processes contributing to land-atmosphere coupling changes over the Sahel derived from changes in models' resolution. Note that it is not intended to represent a particular section and has no meridional and zonal orientation. In the same way, arrow lengths are not proportional to real values, but are only indicative. The arrow color is indicative of model resolution (black for LR, red for HR). The color gradient in LAND indicates the degree of soil saturation from low (brown) to high (green). The labels A, $\mathrm{B}, \mathrm{C}, \mathrm{D}_{\mathrm{d}}$, and $\mathrm{D}_{\mathrm{w}}$ refer to the different steps affecting the coupling (see details in text).

highlights regions where the soil dynamics contributes to drive the surface fluxes, and thereby the overlying atmosphere. The aim is to identify to what extent the processes that arise with enhanced resolution modify the well-known seasonal landatmosphere coupling patterns. While there is not a direct way to support the notion that the increase of model resolution is sufficient to cause, per se, any effect on the land-atmosphere coupling, we consider two possible indirect mechanisms that could explain the differences that emerge at high resolution. First, a local mechanism, where the increase of resolution enhances the spatial variability of prescribed land surface properties, which lead to more heterogeneous spatial patterns of lower boundary conditions (e.g., soil moisture), given the one-dimensional nature of land surface models that simulate them. The occurrence of stronger soil moisture spatial gradients boosts convective instability altering the land-atmosphere feedbacks. Second, a nonlocal mechanism, where high-resolution models improve large-scale circulation upstream of the circulation that governs the precipitation location and timing, thereby affecting land-atmosphere interactions. Following this approach, we undertook a comprehensive process-based analysis of the changes in the Sahel hot spot, to understand the local and nonlocal causes of such changes.

The results show that the low-resolution CMIP6 AMIP-type simulations broadly identify the regions with strong landatmosphere interaction, in agreement with the patterns published by other authors using different methodologies and models (Koster et al. 2004, 2006; Dirmeyer 2011; among others). These hot spots dominate over transition zones with hot semiarid climate, and transition seasons from dry to wet. However, these hot spots are notably sensitive to both resolution and ocean-land-atmosphere coupling. For instance, in MAM the terrestrial coupling index in the Eurasian steppe is increased by about $20 \%$ in AMIP HR and by about $50 \%$ in COUPLED HR. In AMIP-type simulations, the most remarkable effect of the increased resolution is the relocation of some hot spots (e.g., Sahel or sourthern Africa). In COUPLED simulations, the relocation is present, and even more evident in the same regions. However, in other regions, the effect of increasing resolution only strengthens the coupling (e.g., India) or weaken it (e.g., northern Australia).

The Sahel is a region that presents a particular sensitivity to resolution. The resolution enhancement produces an expansion to the north of its land-atmosphere coupling hot spot during summer and autumn in both AMIP and COUPLED simulations. The processbased analysis performed with multiple atmospheric and soil variables presented in section 4a, and simplified in Fig. 10, suggests that the better resolved orography at high resolution increases the easterly moisture flux in summer (step A), but at the same time alters the African easterly jet, favoring its horizontal wind shear, increasing atmospheric instability (step B) and producing more rain over the Sahel (step C). It has a twofold effect: it enhances evapotranspiration in the dry band of the Sahel, where the evaporative regime remains controlled by soil moisture, fortifying the land-atmosphere coupling cycle $\left(\right.$ step $\left.D_{d}\right)$; it weakens the coupling in the southern Sahel, where the increase of water availability produces a shift in the evaporative regime from soil moisture controlled to energy controlled ( $\operatorname{step} \mathrm{D}_{\mathrm{w}}$ ). In the next season (autumn) the atmospheric differences between high- and low-resolution are weak (steps A, B, and C are no longer valid). However, the northward shift in the terrestrial segment of the coupling persists (steps D) due to the soil moisture memory, which retains the same conditions in the soil moisture-evapotranspiration interplay.

It could be argued that previous studies already showed that increased precipitation alter the location of hot spots. However, there is not a full consensus in the scientific community about what the mechanisms behind wetter conditions are. The chain of 
processes that drives precipitation changes in regions with strong land-atmosphere coupling is usually addressed with local mechanisms, considering the land changes (through soil moisture) as the triggering component that favor changes in the overlying atmosphere. Some exceptions to this dominant approach are found in papers focused on the southern Great Plains that highlight a clear dominance of transported moisture in summer precipitation anomalies. Based on a nonlocal perspective and using reanalysis products, Wei and Dirmeyer (2019) reported that summer precipitation in West Africa is sensitive to both local and remote evapotranspiration variations. With a similar perspective but following a different methodology our results also recognize this complementary role of local and nonlocal sources of moisture in generating precipitation and strengthening the coupling, although revealing a primary role of remote mechanisms. In particular, we have shown that coupling processes first depend on atmospheric circulation, which carries moisture from oceans to land and organizes it, to govern the precipitation patterns, and thereby the soil state and surface fluxes, which in turn complement the moisture convergence by feeding back to clouds. Thus, the soil state plays a secondary role related to the persistence of the terrestrial coupling but does not have major impact in the atmospheric leg of the coupling.

Our results also show a remarkable agreement and consistency among CMIP6-HighResMIP GCMs in Sahel in terms of the land-atmosphere coupling sensitivity to resolution, and the chain of mechanisms behind this interplay, especially the predominant role of atmospheric dynamics providing suitable conditions to its onset. Moreover, the model (COUPLED version of MPI-ESM) that does not show an improvement of the atmospheric circulation around Sahel, leading to reduced moisture flux when the resolution is enhanced, also fails in the simulation of land-atmosphere mechanisms. The comparison against TRMM precipitation revealed that this model at high resolution, unlike the rest of the GCMs, amplifies the LR negative precipitation bias in the region. HadGEM3 in SON also presents distinctive features. It is the only model with a clear increase of moisture flux convergence at HR in autumn. The resulting enhancement of precipitation in the domain favors the complete coupling pathway. In other models the increase of moisture convergence at $\mathrm{HR}$ is minimum during autumn, thus the sensitivity of the terrestrial leg to resolution remains the same as in JJA, due to soil memory, but the increase in evapotranspiration has no major effect on precipitation, and thereby, the sensitivity of the atmospheric leg to resolution is weak. These exceptions confirm the primary role of atmospheric conditions in land-atmosphere interactions, giving robustness to the governing mechanisms uncovered, and strengthens the conclusion that most high-resolution GCMs improve the simulation of precipitation in the Sahel, thanks primarily to a better representation of atmospheric dynamics.

To confirm whether the coupling processes that emerge from the high-resolution models are in better agreement with observations, we evaluated precipitation, top-layer soil moisture, and latent heat against satellite-based products. The results show that the overall wetter conditions simulated at high resolution, which cause the relocation of the coupling hot spot, reduce the negative biases of low-resolution simulations in summer and autumn. In particular, precipitation in AMIP-type high-resolution simulations shows a notable agreement with TRMM both in time and space, with percent bias less than $6 \%$. The accurate simulation of precipitation during the rainy season leads to more realistic representation of soil conditions and latent heat. These results reinforce recent studies that support the hypothesis that high-resolution models improve the large-scale circulation, leading to a more accurate representation of regional rainfall in Sahel (Vellinga et al. 2016; Johnson et al. 2016; Vannière et al. 2019; Pante and Knippertz 2019). Thus, the new generation of models provides a good basis to develop more accurate climate predictions in the Sahel, which are essential given its economic dependence on agriculture activities (Garnot et al. 2018), the frequent and intense mesoscale convective systems (Zipser et al. 2006), and the strong link between African easterly waves and Atlantic tropical cyclones (Landsea and Gray 1992; Thorncroft and Hodges 2001; among others).

Acknowledgments. We express our gratitude to the three anonymous reviewers for their detailed and very helpful reviews, which have substantially improved the paper and made our conclusions more robust. This research was supported by the PRIMAVERA project funded by the European Union's Horizon 2020 Research and Innovation Programme under Grant Agreement 641727.

\section{REFERENCES}

Balsamo, G., A. Beljaars, K. Scipal, P. Viterbo, B. van den Hurk, M. Hirschi, and A. K. Betts, 2009: A revised hydrology for the ECMWF model: Verification from field site to terrestrial water storage and impact in the integrated forecast system. J. Hydrometeor., 10, 623-643, https://doi.org/10.1175/2008JHM1068.1.

Basara, J. B., and J. I. Christian, 2018: Seasonal and interannual variability of land-atmosphere coupling across the southern Great Plains of North America using the North American regional reanalysis. Int. J. Climatol., 38, 964-978, https:// doi.org/10.1002/joc.5223.

Beck, H. E., A. I. J. M. van Dijk, V. Levizzani, J. Schellekens, D. G. Miralles, B. Martens, and A. de Roo, 2017: MSWEP: 3-hourly $0.25^{\circ}$ global gridded precipitation (1979-2015) by merging gauge, satellite, and reanalysis data. Hydrol. Earth Syst. Sci., 21, 589-615, https://doi.org/10.5194/hess-21-589-2017.

, N. E. Zimmermann, T. R. McVicar, N. Vergopolan, A. Berg, and E. F. Wood, 2018: Present and future Köppen-Geiger climate classification maps at $1-\mathrm{km}$ resolution. Sci. Data, 5, 180214, https://doi.org/10.1038/sdata.2018.214.

Best, M., and Coauthors, 2011: The Joint UK Land Environment Simulator (JULES), model description-Part I: Energy and water fluxes. Geosci. Model Dev., 4, 677-699, https://doi.org/ 10.5194/gmd-4-677-2011.

Brutel-Vuilmet, C., M. Ménégoz, and G. Krinner, 2013: An analysis of present and future seasonal Northern Hemisphere land snow cover simulated by CMIP5 coupled climate models. Cryosphere, 7, 67-80, https://doi.org/10.5194/tc-7-67-2013.

Burpee, R. W., 1972: The origin and structure of easterly waves in the lower troposphere of North Africa. J. Atmos. Sci. 29, 77-90, https:// doi.org/10.1175/1520-0469(1972)029<0077:TOASOE>2.0.CO;2.

Carlson, T., 1969a: Some remarks on African disturbances and their progress over the tropical Atlantic. Mon. Wea. Rev., 97, 
716-726, https://doi.org/10.1175/1520-0493(1969)097<0716: SROADA $>2.3 . \mathrm{CO} ; 2$.

- 1969b: Synoptic histories of three African disturbances that developed into Atlantic hurricanes. Mon. Wea. Rev., 97, 256-276, https:// doi.org/10.1175/1520-0493(1969)097<0256:SHOTAD>2.3.CO;2.

Chiang, J., Y. Kushnir, and A. Giannini, 2002: Deconstructing Atlantic intertropical convergence zone variability: Influence of the local cross-equatorial sea surface temperature gradient and remote forcing from the eastern equatorial Pacific. J. Geophys. Res., 107, 4004, https://doi.org/10.1029/2000JD000307.

Cullen, M., 1991: The Unified Forecast/Climate Model. Seminar on Numerical Methods in Atmospheric Models, Shinfield Park, Reading, United Kingdom, ECMWF, 233-260, https://www. ecmwf.int/node/8836.

Demory, M.-E., P. L. Vidale, M. Roberts, P. Berrisford, J. Strachan, R. Schiemann, and M. Mizielinski, 2014: The role of horizontal resolution in simulating drivers of the global hydrological cycle. Climate Dyn., 42, 2201-2225, https://doi.org/10.1007/s00382013-1924-4.

Diedhiou, A., S. Janicot, A. Viltard, P. de Felice, and H. Laurent, 1999: Easterly wave regimes and associated convection over West Africa and tropical Atlantic: Results from the NCEP/ NCAR and ECMWF reanalyses. Climate Dyn., 15, 795-822, https://doi.org/10.1007/s003820050316.

Dirmeyer, P. A., 2000: Using a global soil wetness dataset to improve seasonal climate simulation. J. Climate, 13, 2900-2922, https://doi.org/10.1175/1520-0442(2000)013<2900:UAGSWD> 2.0.CO;2.

_ 2011: The terrestrial segment of soil moisture-climate coupling. Geophys. Res. Lett., 38, L16702, https://doi.org/10.1029/ 2011GL048268.

_ Z Z. Wang, M. J. Mbuh, and H. E. Norton, 2014: Intensified land surface control on boundary layer growth in a changing climate. Geophys. Res. Lett., 41, 1290-1294, https://doi.org/ 10.1002/2013GL058826.

Dorigo, W., and Coauthors, 2017: ESA CCI soil moisture for improved earth system understanding: State-of-the art and future directions. Remote Sens. Environ., 203, 185-215, https:// doi.org/10.1016/j.rse.2017.07.001.

Douville, H., S. Conil, S. Tyteca, and A. Voldoire, 2007: Soil moisture memory and West African monsoon predictability: Artefact or reality? Climate Dyn., 28, 723-742, https://doi.org/ 10.1007/s00382-006-0207-8.

Eltahir, E. A., 1998: A soil moisture-rainfall feedback mechanism: 1. Theory and observations. Water Resour. Res., 34, 765-776, https://doi.org/10.1029/97WR03499.

Findell, K. L., P. Gentine, B. R. Lintner, and B. P. Guillod, 2015: Data length requirements for observational estimates of landatmosphere coupling strength. J. Hydrometeor., 16, 16151635, https://doi.org/10.1175/JHM-D-14-0131.1.

Fischer, E., S. Seneviratne, P. L. Vidale, D. Lüthi, and C. Schär, 2007: Soil moisture-atmosphere interactions during the 2003 European summer heat wave. J. Climate, 20, 5081-5099, https://doi.org/10.1175/JCLI4288.1.

Garnot, V. S. F., A. Groth, and M. Ghil, 2018: Coupled climateeconomic modes in the Sahel's interannual variability. Ecol. Econ., 153, 111-123, https://doi.org/10.1016/j.ecolecon.2018.07.006.

Gruber, A., W. A. Dorigo, W. Crow, and W. Wagner, 2017: Triple collocation-based merging of satellite soil moisture retrievals. IEEE T. Geosci. Remote, 55, 6780-6792, https://doi.org/ 10.1109/TGRS.2017.2734070.

_, T. Scanlon, R. van der Schalie, W. Wagner, and W. Dorigo, 2019: Evolution of the ESA CCI soil moisture climate data records and their underlying merging methodology. Earth Syst. Sci. Data, 11, 717-739, https://doi.org/10.5194/essd-11-717-2019. Guillod, B. P., B. Orlowsky, D. G. Miralles, A. J. Teuling, and S. I. Seneviratne, 2015: Reconciling spatial and temporal soil moisture effects on afternoon rainfall. Nat. Commun., 6, 6443, https://doi.org/10.1038/ncomms7443.

Guo, Z., and P. A. Dirmeyer, 2013: Interannual variability of landatmosphere coupling strength. J. Hydrometeor., 14, 16361646, https://doi.org/10.1175/JHM-D-12-0171.1.

— and Coauthors, 2006: GLACE: The Global Land-Atmosphere Coupling Experiment. Part II: Analysis. J. Hydrometeor., 7, 611-625, https://doi.org/10.1175/JHM511.1.

_ P. A. Dirmeyer, and T. DelSole, 2011: Land surface impacts on subseasonal and seasonal predictability. Geophys. Res. Lett., 38, L24812, https://doi.org/10.1029/2011GL049945.

Gutjahr, O., D. Putrasahan, K. Lohmann, J. H. Jungclaus, J.-S. von Storch, N. Brüggemann, H. Haak, and A. Stössel, 2019: Max Planck Institute Earth System Model (MPI-ESM1.2) for the High-Resolution Model Intercomparison Project (HighResMIP). Geosci. Model Dev., 12, 3241-3281, https://doi.org/10.5194/gmd-12-3241-2019.

Haarsma, R., and Coauthors, 2016: High Resolution Model Intercomparison Project (HighResMIP v1. 0) for CMIP6. Geosci. Model Dev., 9, 4185-4208, https://doi.org/10.5194/ gmd-9-4185-2016.

Hagemann, S., and T. Stacke, 2015: Impact of the soil hydrology scheme on simulated soil moisture memory. Climate Dyn., 44, 1731-1750, https://doi.org/10.1007/s00382-014-2221-6.

Hazeleger, W., and Coauthors, 2010: EC-Earth: A seamless Earth system prediction approach in action. Bull. Amer. Meteor. Soc., 91, 1357-1364, https://doi.org/10.1175/2010BAMS2877.1.

Holgate, C. M., A. I. J. M. Van Dijk, J. P. Evans, and A. J. Pitman, 2019: The importance of the one-dimensional assumption in soil moisture-rainfall depth correlation at varying spatial scales. J. Geophys. Res. Atmos., 124, 2964-2975, https://doi.org/ 10.1029/2018JD029762.

Huffman, G. J., and Coauthors, 2007: The TRMM Multisatellite Precipitation Analysis (TMPA): Quasi-global, multiyear, combinedsensor precipitation estimates at fine scales. J. Hydrometeor., 8, 38-55, https://doi.org/10.1175/JHM560.1.

Johnson, S. J., and Coauthors, 2016: The resolution sensitivity of the South Asian monsoon and Indo-Pacific in a global 0.35 AGCM. Climate Dyn., 46, 807-831, https://doi.org/10.1007/ s00382-015-2614-1.

Jung, M., and Coauthors, 2019: The FLUXCOM ensemble of global land-atmosphere energy fluxes. Sci. Data, 6, 74, https:// doi.org/10.1038/s41597-019-0076-8.

Jungclaus, J., and Coauthors, 2013: Characteristics of the ocean simulations in the Max Planck Institute Ocean Model (MPIOM) the ocean component of the MPI-Earth system model. J. Adv. Model. Earth Syst., 5, 422-446, https://doi.org/10.1002/jame.20023.

Koster, R. D., and M. J. Suarez, 2001: Soil moisture memory in climate models. J. Hydrometeor., 2, 558-570, https://doi.org/ 10.1175/1525-7541(2001)002<0558:SMMICM > 2.0.CO;2.

$\longrightarrow$, and — 2003: Impact of land surface initialization on seasonal precipitation and temperature prediction. J. Hydrometeor., 4, 408-423, https:/doi.org/10.1175/1525-7541(2003)4<408:IOLSIO>2.0.CO;2.

$\longrightarrow, \ldots$, and M. Heiser, 2000: Variance and predictability of precipitation at seasonal-to-interannual timescales. J. Hydrometeor., 1, 26-46, https://doi.org/10.1175/1525-7541(2000)001<0026: VAPOPA $>2.0 . \mathrm{CO} ; 2$.

, P. A. Dirmeyer, A. N. Hahmann, R. Ijpelaar, L. Tyahla, P. Cox, and M. J. Suarez, 2002: Comparing the degree of land-atmosphere interaction in four atmospheric general 
circulation models. J. Hydrometeor., 3, 363-375, https://doi.org/ 10.1175/1525-7541(2002)003<0363:CTDOLA $>2.0 . C O ; 2$.

— , and Coauthors, 2004: Regions of strong coupling between soil moisture and precipitation. Science, 305, 1138-1140, https:// doi.org/10.1126/science.1100217.

— , and Coauthors, 2006: GLACE: The Global Land-Atmosphere Coupling Experiment. Part I: Overview. J. Hydrometeor., 7, 590-610, https://doi.org/10.1175/JHM510.1.

,- S. Schubert, and M. Suarez, 2009: Analyzing the concurrence of meteorological droughts and warm periods, with implications for the determination of evaporative regime. J. Climate, 22, 3331-3341, https://doi.org/10.1175/2008JCLI2718.1.

— zation to subseasonal forecast skill: First results from a multimodel experiment. Geophys. Res. Lett., 37, L02402, https:// doi.org/10.1029/2009GL041677.

— , and Coauthors, 2011: The second phase of the global landatmosphere coupling experiment: Soil moisture contributions to subseasonal forecast skill. J. Hydrometeor., 12, 805-822, https://doi.org/10.1175/2011JHM1365.1.

Lafore, J.-P., C. Flamant, V. Giraud, F. Guichard, P. Knippertz, J.-F. Mahfouf, P. Mascart, and E. R. Williams, 2010: Introduction to the AMMA special issue on 'Advances in understanding atmospheric processes over West Africa through the AMMA field campaign.' Quart. J. Roy. Meteor. Soc., 136, 2-7, https://doi.org/10.1002/qj.583.

Landsea, C. W., and W. M. Gray, 1992: The strong Association between western Sahelian monsoon rainfall and intense Atlantic hurricanes. J. Climate, 5, 435-453, https://doi.org/ 10.1175/1520-0442(1992)005<0435:TSABWS>2.0.CO;2.

Madec, G., P. Delecluse, M. Imbard, and C. Levy, 2008: NEMO ocean engine. Institut Pierre-Simone Laplace Note du Pôle de Modelisation 27, 396 pp., https://www.nemo-ocean.eu/wpcontent/uploads/NEMO_book.pdf.

Mauritsen, T., and Coauthors, 2019: Developments in the MPI-M Earth System Model version 1.2 (MPI-ESM1. 2) and its response to increasing $\mathrm{CO}_{2}$. J. Adv. Model. Earth Syst., 11, 9981038, https://doi.org/10.1029/2018MS001400.

Moufouma-Okia, W., and D. P. Rowell, 2010: Impact of soil moisture initialisation and lateral boundary conditions on regional climate model simulations of the West African monsoon. Climate Dyn., 35, 213-229, https://doi.org/10.1007/s00382009-0638-0.

Müller, O. V., E. H. Berbery, D. Alcaraz-Segura, and M. B. Ek, 2014: Regional model simulations of the 2008 drought in southern South America using a consistent set of land surface properties. J. Climate, 27, 6754-6778, https://doi.org/10.1175/JCLI-D-13-00463.1.

Pante, G., and P. Knippertz, 2019: Resolving Sahelian thunderstorms improves mid-latitude weather forecasts. Nat. Commun., 10, 3487, https://doi.org/10.1038/s41467-019-11081-4.

Qiu, S., and I. N. Williams, 2020: Observational evidence of statedependent positive and negative land surface feedback on afternoon deep convection over the southern Great Plains. Geophys. Res. Lett., 47, e2019GL086622, https://doi.org/10.1029/2019GL086622.

Quesada, B., R. Vautard, P. Yiou, M. Hirschi, and S. Seneviratne, 2012: Asymmetric European summer heat predictability from wet and dry southern winters and springs. Nat. Climate Change, 2, 736-741, https://doi.org/10.1038/nclimate1536.

Roberts, C., R. Senan, F. Molteni, S. Boussetta, M. Mayer, and S. Keeley, 2018: Climate model configurations of the ECMWF Integrated Forecasting System (ECMWF-IFS cycle 43r1) for HighResMIP. Geosci. Model Dev., 11, 3681-3712, https:// doi.org/10.5194/gmd-11-3681-2018.
Rowell, D., C. Folland, K. Maskell, and M. Ward, 1995: Variability of summer rainfall over tropical North Africa (1906-92): Observations and modelling. Quart. J. Roy. Meteor. Soc., 121, 669-704, https://doi.org/10.1002/qj.49712152311.

Ruiz-Barradas, A., and S. Nigam, 2013: Atmosphere-land surface interactions over the southern Great Plains: Characterization from pentad analysis of DOE ARM field observations and NARR. J. Climate, 26, 875-886, https://doi.org/10.1175/JCLI-D-11-00380.1.

Santanello, J. A., C. Ferguson, M. Ek, P. Dirmeyer, O. Tuinenburg, C. Jacobs, C. van Heerwaarden, and B. Findell, 2011a: Local Land-atmosphere Coupling (LoCo) research: Status and results. GEWEX News, Vol. 21, No. 4, International GEWEX Project Office, Silver Spring, MD, 7-9, www.gewex.org/ gewex-content/files_mf/1432209597Nov2011.pdf.

, C. D. Peters-Lidard, and S. V. Kumar, 2011b: Diagnosing the sensitivity of local land-atmosphere coupling via the soil moisture-boundary layer interaction. J. Hydrometeor., 12, 766-786, https://doi.org/10.1175/JHM-D-10-05014.1.

— , and Coauthors, 2018: Land-atmosphere interactions: The LoCo perspective. Bull. Amer. Meteor. Soc., 99, 1253-1272, https://doi.org/10.1175/BAMS-D-17-0001.1.

Seneviratne, S. I., D. Lüthi, M. Litschi, and C. Schär, 2006: Landatmosphere coupling and climate change in Europe. Nature, 443, 205-209, https://doi.org/10.1038/nature05095.

— , T. Corti, E. Davin, M. Hirschi, E. Jaeger, I. Lehner, B. Orlowsky, and A. Teuling, 2010: Investigating soil moisture-climate interactions in a changing climate: A review. Earth-Sci. Rev., 99, 125161, https://doi.org/10.1016/j.earscirev.2010.02.004.

— backs on CMIP5 projections: First results from the GLACECMIP5 experiment. Geophys. Res. Lett., 40, 5212-5217, https://doi.org/10.1002/grl.50956.

Su, H., Z.-L. Yang, R. E. Dickinson, and J. Wei, 2014: Spring soil moisture-precipitation feedback in the southern Great Plains: How is it related to large-scale atmospheric conditions? Geophys. Res. Lett., 41, 1283-1289, https://doi.org/10.1002/2013GL058931.

Sylla, M., I. Diallo, and J. S. Pal, 2013: West African monsoon in state-ofthe-science regional climate models. Climate Variability-Regional and Thematic Patterns, A. Tarhule, Ed., InTech, 3-36, https:// doi.org/10.5772/55140.

Taylor, C. M., R. A. de Jeu, F. Guichard, P. P. Harris, and W. A. Dorigo, 2012: Afternoon rain more likely over drier soils. Nature, 489, 423-426, https://doi.org/10.1038/nature11377.

Thorncroft, C., and K. Hodges, 2001: African easterly wave variability and its relationship to Atlantic tropical cyclone activity. J. Climate, 14, 1166-1179, https://doi.org/10.1175/1520-0442(2001)014<1166: AEWVAI $>2.0 . \mathrm{CO} ; 2$.

Titchner, H., and N. Rayner, 2014: The met office hadley centre sea ice and sea surface temperature data set, version 2: 1 . Sea ice concentrations. J. Geophys. Res. Atmos., 119, 2864-2889, https://doi.org/10.1002/2013JD020316.

TRMM, 2011: TRMM (TMPA/3b43) rainfall estimate 131 month 0.25 degree $\times 0.25$ degree v7. GES DISC, accessed 28 July 2020, https://doi.org/10.5067/TRMM/TMPA/MONTH/7.

Ukkola, A. M., A. J. Pitman, M. G. Donat, M. G. De Kauwe, and O. Angélil, 2018: Evaluating the contribution of land-atmosphere coupling to heat extremes in CMIP5 models. Geophys. Res. Lett., 45, 9003-9012, https://doi.org/10.1029/2018GL079102.

van der Linden, E., R. Haarsma, and G. van der Schrier, 2019: Impact of climate model resolution on soil moisture projections in central-western Europe. Hydrol. Earth Syst. Sci., 23, 191-206, https://doi.org/10.5194/hess-23-191-2019. 
Vannière, B., and Coauthors, 2019: Multi-model evaluation of the sensitivity of the global energy budget and hydrological cycle to resolution. Climate Dyn., 52, 6817-6846, https://doi.org/ 10.1007/s00382-018-4547-y.

Vellinga, M., M. Roberts, P. L. Vidale, M. Mizielinski, M.-E. Demory, R. Schiemann, J. Strachan, and C. Bain, 2016: Sahel decadal rainfall variability and the role of model horizontal resolution. Geophys. Res. Lett., 43, 326-333, https://doi.org/ 10.1002/2015GL066690.

Wei, J., and P. A. Dirmeyer, 2012: Dissecting soil moistureprecipitation coupling. Geophys. Res. Lett., 39, L19711, https:// doi.org/10.1029/2012GL053038.

- , and — 2019: Sensitivity of land precipitation to surface evapotranspiration: A nonlocal perspective based on water vapor transport. Geophys. Res. Lett., 46, 12 588-12 597, https:// doi.org/10.1029/2019GL085613.

—_, H. Su, and Z.-L. Yang, 2016: Impact of moisture flux convergence and soil moisture on precipitation: A case study for the southern United States with implications for the globe. Climate Dyn., 46, 467-481, https://doi.org/10.1007/s00382015-2593-2.

Welty, J., and X. Zeng, 2018: Does soil moisture affect warm season precipitation over the southern Great Plains?
Geophys. Res. Lett., 45, 7866-7873, https://doi.org/10.1029/ 2018 GL078598.

—, S. Stillman, X. Zeng, and J. Santanello Jr., 2020: Increased likelihood of appreciable afternoon rainfall over wetter or drier soils dependent upon atmospheric dynamic influence. Geophys. Res. Lett., 47, e2020GL087779, https://doi.org/ 10.1029/2020GL087779.

Williams, K., and Coauthors, 2018: The Met Office Global Coupled Model 3.0 and 3.1 (GC3.0 and GC3.1) configurations. J. Adv. Model. Earth Syst., 10, 357-380, https://doi.org/ 10.1002/2017MS001115.

Wu, W., and R. Dickinson, 2004: Time scales of layered soil moisture memory in the context of land-atmosphere interaction. J. Climate, 17, 2752-2764, https://doi.org/10.1175/15200442(2004)017<2752:TSOLSM>2.0.CO;2.

Zampieri, M., F. D. Ándrea, R. Vautard, P. Ciais, N. de NobletDucoudré, and P. Yiou, 2009: Hot European summers and the role of soil moisture in the propagation of Mediterranean drought. J. Climate, 22, 4747-4758, https://doi.org/10.1175/ 2009JCLI2568.1.

Zipser, E. J., D. J. Cecil, C. Liu, S. W. Nesbitt, and D. P. Yorty, 2006: Where are the most intense thunderstorms on Earth? Bull. Amer. Meteor. Soc., 87,1057-1072, https://doi.org/10.1175/ BAMS-87-8-1057. 